\title{
Kainate-type of glutamate receptors regulate wiring of intrinsic glutamatergic connectivity in the amygdala
}

Maria Ryazantseva ${ }^{1,2}$, Jonas Englund ${ }^{1,2}$, Alexandra Shintyapina ${ }^{1,2}$, Johanna Huupponen ${ }^{1,2}$, Asla Pitkänen ${ }^{3}$, Juha M. Partanen ${ }^{1}$, Sari E. Lauri 1,2*

1. Molecular and Integrative Biosciences Research Program, University of Helsinki, Finland

2. Neuroscience Center, University of Helsinki, Finland

3. A.I. Virtanen Institute for M olecular Sciences, University of Eastern Finland, Finland

* Lead contact and Corresponding author, e-mail sari.lauri@ helsinki.fi

\section{Summary}

Perturbed information processing in the amygdala has been implicated in developmentally originating neuropsychiatric disorders. However, little is known on the mechanisms that guide formation and refinement of intrinsic connections between amygdaloid nuclei. We demonstrate that the glutamatergic connection from basolateral to central amygdala (BLA-CeA) develops rapidly during the first ten postnatal days, before external inputs underlying amygdala dependent behaviors emerge. During this restricted period of synaptic development, kainate-type of ionotropic glutamate receptors (KARs) are highly expressed in the BLA and tonically activated to regulate glutamate release via a G-protein dependent mechanism. Genetic manipulation of this endogenous KAR activity locally in the newborn LA perturbed development of glutamatergic input to CeA, identifying KARs as a physiological mechanism regulating wiring of the intrinsic glutamatergic circuitry in the amygdala.

Keywords $(<10)$

kainate receptor; glutamate receptor; amygdala; synaptic transmission; circuit development 


\section{Introduction}

Kainate-type of ionotropic glutamate receptors (KARs) are expressed in different cell types in various parts of the brain. While physiological roles for KARs in modulation of both glutamatergic and GABAergic transmission have been described in the mature neural networks (Lerma $\& M$ arquez, 2013), increasing evidence suggests predominant functions for KARs in the developing circuitry. KARs modulate formation of glutamatergic contacts by regulating neurite growth (Ibarretxe et al., 2007; Joseph et al., 2011; M arquez et al., 2013), filopodial dynamics (Chang and De Camilli, 2001; Tashiro et al., 2006) and synaptic differentiation (Marchal and Mulle, 2004; Lanore et al., 2012; Sakha et al. 2016). At immature hippocampal synapses, KARs control efficacy and short-term dynamics of transmission by tonically regulating glutamate release probability (Lauri et al., 2005; 2006). Interestingly, many of the developmental functions of KARs are mediated by non-canonical G-protein dependent signaling mechanisms (Lauri et al., 2006; Tashiro et al., 2006; Marquez et al 2013). In the absence of the early KAR activity, development of the glutamatergic connectivity in the hippocampus is perturbed (Vesikansa et al., 2012; Lanore et al., 2012; Orav et al., 2017). Thus, the existing data indicate KARs as key modulators of synaptic transmission and plasticity during the critical window of synapse development in the hippocampus. However, the applicability of these mechanisms to other areas of the developing brain remains largely unknown.

Amygdala represents another part of the limbic system involved in memory, emotion and autonomic function. Basic architecture of the mammalian amygdala is present at birth, but similar to hippocampus, it undergoes structural and functional change across extended developmental period (Tottenham and Sheridan, 2010). External inputs to basolateral amygdala (BLA) develop postnatally, the thalamic inputs being detectable in around P7 (Bouwmeester et al., 2002), while cortical innervation emerge gradually between P10 - P21 (Arruda - Carvalho et al., 2017). Both lateral (LA) and basal amygdala (BA) nuclei have strong glutamatergic projections to the central amygdala (CeA), where the principal cells are GABAergic (Sah et al., 2003; Pape and Pare, 2010). However, practically nothing is known on the development of the intrinsic connections in the amygdala.

Here we show that KAR subunits GluK1,2 and 5 are strongly expressed in the amygdala during early postnatal development, temporally coinciding with rapid development of functional glutamatergic synapses. In the newborn BLA, KARs are physiologically activated to regulate glutamate release probability via a G-protein dependent mechanisms. Knockdown or overexpression of GluK1 expression locally in the newborn LA perturbed development of glutamatergic input to CeA, suggesting that endogenous KAR activity is critical for development of the LA-CeA connections. Interestingly, it was recently shown that enhanced activity of KARs in the adult amygdala, generated via GluK4 overexpression, leads to severe changes in the circuit excitability and amygdala dependent behaviors (Arora et al., 2018). Together, these data thus identify tonic KAR activity as a mechanism modulating behaviorally relevant synaptic connectivity within the amygdala. 


\section{Results}

Kainate receptors are highly expressed in the BLA during the first postnatal week

Based on the existing literature, at least subunits GluK1, GluK2 and GluK5 are expressed in the adult rat BLA (Bettler et al., 1990; Li et al., 2001) where they have been implicated in regulation of synaptic transmission and plasticity (Li et al., 2001; Ko et al., 2005; Shin et al., 2010). To characterize the developmental profile for expression of various KAR subunits, BLA was dissected from acute rat brain slices at three developmental stages (postnatal day (P)4, P14, and P50). Absolute quantitative RT-PCR analysis of KAR mRNA levels revealed that during early postnatal development (P4), the predominant KAR subunits expressed in the BLA are GluK1, GluK2 and GluK5, while the subunits GluK3 and GluK4 were detected at low levels. During development, GluK2 and GluK5 mRNA expression remained relatively high (at P14 and P50, GluK2 : $67 \pm 7 \%$ and $69 \pm 26 \%$; GluK5 $91 \pm 16$ $\%$ and $163 \pm 26 \%$, of the level at P4) while GluK1 and GluK4 mRNA levels were significantly downregulated already during the first two postnatal weeks (P14, $32 \pm 11 \%, p<0.001$, ANOVA and $54 \pm 16 \%, p<0.001$, ANOVA on ranks, of the level at P4, respectively). GluK3 mRNA expression was undetectable at P14 and P50. Finally, the KAR auxiliary subunits NETO1 and NETO2 mRNA were both detected in the neonatal BLA, NETO2 representing the predominant subtype (Figure $1 A, B$ ).

To verify KAR expression at protein level, Western blot was done from crude protein extracts from neonatal BLA using antibodies for GluK2/3 and GluK5. These antibodies have been previously validated using knockout tissue as a negative control (Ruiz et al., 2005; Wyeth et al., 2014). Unfortunately, selective specific antibodies for other KAR subunits are not available. Consistent with the qPCR data, GluK2/3 and GluK5 were clearly detected both at P4 and P14 BLA, at approximately the same levels (Figure $1 \mathrm{C}$ ).

KARs localize to both glutamatergic and GABAergic neurons in the neonatal amygdala

In situ hybridization (ISH) using fluorescent probes was used to study the pattern of KAR subunit expression in the amygdala in more detail. ISH signal in the various nuclei of the amygdala was analyzed in rat brain sections, cut from P4 and P14. In addition, sections from Gad67GF/+transgenic mice were analyzed to investigate the expression of various KAR subunits in GAD67GFP+GABAergic neurons.

At P4, mRNAs encoding subunits GluK1, GluK2 and GluK5 were detected in all the amygdala nuclei analyzed (LA, BA and CeA) (Figure 1D-F). GluK1 mRNA was observed in both GAD67GFP positive (GABAergic) and negative (likely representing glutamatergic principal neurons) cells in the BLA (25 $\pm 5 \%$ of GAD67GFP+ neurons at P4). In the central amygdala, GluK1 ISH signal was detected in $30 \pm$ $2 \%$ of the GAD67GFP positive neurons at P4. Interestingly GluK1 signal was apparently mostly present in those CeA neurons where GAD67GFP staining was weak, possibly representing a lowdifferentiation cell population (Donato et al., 2013). In addition, strong expression of GluK1 was detected in the GABAergic intercalated neurons (ITC) located between BLA and CeA. Consistent with the qPCR data, GluK1 ISH signal was significantly downregulated in all amygdala nuclei during the first postnatal weeks (GluK1 signal at P14 as percentage of P4: LA $17 \pm 6 \%, p<0.05$, ANOVA on ranks; 
BA $43 \pm 12 \%, p<0.05$, ANOVA on ranks; CeA $31 \pm 8 \%, p<0.005$, ANOVA on ranks; ITC $22 \pm 4 \%, p<$ 0.05, ANOVA).

GluK2 mRNA was predominantly expressed in the GAD67GFP negative (glutamatergic) cells, and only detected in few GABAergic neurons within the BLA (18 $\pm 3 \%$ of GAD67GFP+ neurons at P4). Within the BLA, GluK2 expression was predominant in the lateral part. GluK2 mRNA was detected in a large population of GABAergic neurons in the CeA (42\% of GAD67GFP+ neurons at P4) and also at the ITC neurons. GluK2 expression was slightly downregulated during development, although this effect reached statistical significance only in the LA and ITC (GluK2 signal at P14 as percentage of P4: LA $71 \pm$ 10\%, p <0.005, ANOVA; BA $66 \pm 37 \%$; CeA $31 \pm 8 \%$; ITC $62 \pm 13 \%$, p <0.05, ANOVA) (Figure 1D-F).

GluK5 mRNA was detected in both GAD67GFP positive and negative cells ( $30 \pm 2 \%$ of GAD67GFP+ neurons at $\mathrm{P} 4)$ in the BLA. GluK5 was also strongly expressed in most ( $43 \pm 6 \%$ ) neurons in the CeA at P4. At P14, the same overall pattern of staining remained, except for significant downregulation of GluK5 expression level in the CeA (GluK5 signal at P14 as percentage of P4: LA $96 \pm 31 \%$, BA $97 \pm$ 20\%; CeA $53 \pm 12 \%$ p < 0.01, ANOVA; ITC $80 \pm 18 \%$ ) (Figure 1D-F).

\section{Early postnatal development of glutamatergic synaptic connectivity in the amygdala}

The high developmental expression of KAR subunits in the amygdala is similar to that in the hippocampus, where KARs have specific developmentally restricted functions related to maturation of the glutamatergic synaptic connectivity. However, the exact time course for development of glutamatergic synaptic inputs to various nuclei in the amygdala is not known. Therefore, we recorded miniature excitatory postsynaptic currents (mEPSCs) from LA, BA and CeA neurons to get a general view on the functional glutamatergic inputs at different stages of postnatal development. The recorded cells were filled with biocytin for post-hoc analysis of the spine density.

Interestingly, the mean mEPSC frequency, reflecting the density of functional glutamatergic inputs to the recorded neuron, increased with a distinct developmental time course at different nuclei. In the LA and BA, the mEPSC frequency increased significantly from P4-7 to P9-11 (LA, $479 \pm 88 \%, p<$ 0.001 , ANOVA on ranks; BA , $566 \pm 108 \%, p<0.001$, ANOVA on ranks), and from P9-11 to P14-16 (LA $240 \pm 50 \%, p<0.05$, ANOVA on ranks; BA $147 \pm 23 \%, p<0.05$, ANOVA on ranks), but reached a plateau at the second postnatal week (Figure $2 \mathrm{~A}, \mathrm{~B}$ ). In contrast, in the CeA the mEPSC frequency increased rapidly between P4-7 and P9-11 (353 $\pm 62 \%, p<0.001$, ANOVA on ranks), after which no significant changes in the mean frequency of the events were detected within the analyzed time window (Figure $2 \mathrm{~A}, \mathrm{~B}$ ). The mEPSC amplitudes remained stable throughout the early postnatal development (not shown).

Since the mean mEPSC frequency might be affected by factors other than synapse number, we also investigated the density of dendritic spines from the biocytin filled neurons. Spine maturation takes place later than formation of a functional synapse. However, the mean spine density appeared to stabilize in the CeA earlier as compared to BLA (spine density, \% increase P4-7 vs P9-11: LA $406 \pm$ 
$60 \%, p<0.05$ ANOVA on ranks; BA $303 \pm 63 \%, p<0.05$, ANOVA on ranks; CeA $273 \pm 50, p<0.05$, ANOVA on ranks; P14-16 vs P20-21: $143 \pm 13 \%, \mathrm{p}<0.05$, ANOVA; BA $166 \pm 25 \%, \mathrm{p}<0.05$, ANOVA; CeA $94 \pm 7 \%$; Figure $2 \mathrm{C}, \mathrm{D})$. This is consistent with the idea that the glutamatergic synapses to $\mathrm{CeA}$ form rapidly during the first two postnatal weeks in rodent, while the inputs to BLA develop with an extended time course.

Ionotropic KAR function is not detected in the BLA during the first postnatal week

The developmental peak in KAR, and particularly GluK1 expression was associated with the time of rapid development of glutamatergic synapses in the BLA and CeA. To understand the physiological roles of KARs in the developing circuit, we mapped functional ionotropic KARs in the neonatal amygdala using agonist application during voltage clamp recordings. Surprisingly, application of kainate $(K A, 2 \mu M)$ in the presence of selective antagonists for AM PA, NM DA and GABA receptors $(2 \mu \mathrm{M} \mathrm{NBQX}, 50 \mu \mathrm{M}$ APV and $100 \mu \mathrm{M}$ PiTX, respectively) induced no or only a very small current (LA: $6 \pm 1 \mathrm{pA}$; BA: $8 \pm 1 \mathrm{pA}$ ) in the BLA neurons during the first postnatal week (P4-P7), while a marked inward current was observed later on in development (P14-P16) (LA: $81 \pm 19$ pA, BA $37 \pm 5$ pA) (Figure $3 A, B)$. In the CeA, a small KA induced inward current was detected already at P4-P6 (15 \pm 2 $p A)$, but the current was significantly larger at P14-16 (27 $\pm 3 p A, p<0.05$, ANOVA) (Figure $3 A, B)$. Since kainate might cause rapid desensitization of the receptors, we also used another KAR agonist, domoate to confirm the result in the first postnatal week (P4-P7). Application of domoate (500 nM) induced no current in LA neurons ( $4 \pm 1 \mathrm{pA})$, but in BA a small inward current was detected (17 \pm 1 pA)(Figure $3 \mathrm{C}, \mathrm{D})$. Thus, the high expression of the KAR subunits in the newborn LA does not correlate with ionotropic function of KARs, which emerges after the second postnatal week. Small KA-induced currents were detected in BA and in particular, in the CeA already at P4-P6, but contrast to the declining mRNA expression profile, the ionotropic function increased towards the second postnatal week.

KARs regulate glutamatergic inputs to $\mathrm{BA}$ and $\mathrm{CeA}$ during the first postnatal week

At immature CA3-CA1 synapses, presynaptic GluK1 subunit containing KARs tonically regulate glutamate release probability in a G-protein and PKC-dependent manner (Lauri et al., 2006; Sallert et al., 2007). To test whether KARs might have similar functions in the newborn amygdala, we studied the effect of $200 \mathrm{nM}$ ACET, a selective antagonist for GluK1 subunit containing KARs (Dargan et al., 2009), on mEPSCs in LA, BA and CeA during first (P4-7) and second postnatal weeks (P10-16). In LA, ACET had no effect on mEPSCs at P4-6 (frequency $92 \pm 14 \%$, amplitude $101 \pm 8 \%$ of control) but slightly depressed mEPSC frequency at P14-P16 (frequency $89 \pm 3 \%$ of control, $p<0.05$, paired t-test; amplitude $103 \pm 4 \%$ of control; Figure $4 \mathrm{~A}$ ). In contrast, ACET application resulted in a significant increase in the mEPSC frequency in BA at P4-P6 ( $130 \pm 4 \%$ of control, $p<0.05$, paired ttest), but not at P14-P16 (92 $\pm 7 \%$ ) (Figure 4B). ACET had no effect on mEPSC amplitude at either developmental time point ( $97 \pm 1 \%$ and $100 \pm 4 \%$ of control, respectively). The developmentally restricted effect of GluK1 KAR antagonism on mEPSC frequency in BA is similar to that previously 
characterized in the area CA1 of hippocampus (Lauri et al., 2006), indicative of tonic KAR mediated inhibition of glutamate release.

In CeA, ACET application resulted in a robust depression of mEPSC frequency in first postnatal week (P5-6) (73 $\pm 5 \%, p<0.01$, paired t-test) without affecting their amplitude ( $99 \pm 3 \%$ ). Also this effect was developmentally restricted, as ACET had no effect of mEPSCs at P10-P11 CeA (frequency $101 \pm$ $7 \%$, amplitude $98 \pm 4 \%$; Figure 4C).

These data show that GluK1 subunit containing KARs are physiologically activated to regulate glutamatergic transmission in the amygdala during the first postnatal week. Their effect is area and/or cell type specific, with KAR mediated inhibition and facilitation of transmission at glutamatergic inputs to $B A$ and $C e A$, respectively.

Transmission at immature BLA - CeA synapses is tonically facilitated by presynaptic G-protein coupled KARs

The data on KAR expression and function at the neonatal amygdala so far show 1 ) high expression of GluK1, GluK2 and GluK5 in the BLA 2) low ionotropic KAR activity in the BLA and 3) KAR dependent regulation of $\mathrm{MEPSC}$ frequency in the $\mathrm{BA}$ and $\mathrm{CeA}$. One interpretation of these data is that GluK1 subunit containing KARs, expressed in the principal cells of LA (and BA), are targeted to axons to regulate transmitter release at emerging projections to $\mathrm{BA}$ and $\mathrm{CeA}$ via a mechanism that does not require ionotropic activity.

To investigate this we focused to study the pathway from BLA to CeA at P5-6, and recoded EPSCS from CeA in response to electrical stimulation of the LA. Consistent with hypothesis that presynaptic GluK1 subunit containing KARs regulate transmission at this pathway, ACET application resulted in significant reversible depression of the EPSC amplitude (60 $\pm 3 \%, p<0.001$, paired t-test) that was associated with an increase in paired - pulse ratio (PPR) $(150 \pm 14 \%, p<0.01$, paired t-test) (Figure $5 A)$. Furthermore, EPSCs evoked by single pulse or paired pulses with 50 ms interval of BLA stimulation were completely blocked by the AM PA-receptor selective antagonist GYKI53655 (25 $\mu \mathrm{M})(12 \pm 3 \%, p<0.001$, paired t-test), excluding the possibility that postsynaptic KARs significantly contributed to the eEPSC in this pathway (Figure 5B). Adult CeA neurons also receive glutamatergic input from extra-amygdalar brain regions, including sensory input from the auditory cortex and thalamus (Keifer et al., 2015). However, during the first postnatal week, we could not observe any postsynaptic responses in CeA neurons to stimulation of external and internal capsulae, the regions containing cortical and thalamic projections to amygdala (not shown). This suggests that external inputs to CeA are not present during the first postnatal week and thus do not contribute to the observed changes in mEPSC frequency in response to KAR antagonism in the neonate (P5-6) CeA.

Pharmacological tools were used to further characterize the mechanism involved. Application of a broad KAR agonist KA (500 nM) and ATPA (1 $\mu \mathrm{M})$, agonist selective for GluK1 subunit containing KARs, resulted in transient increase in mEPSC frequency in P5-P6 CeA (146 $\pm 27 \%$ and $158 \pm 24 \%$, 
respectively, $p<0.05$, paired t-test; Figure 5C,D), with no effect on mEPSC amplitude $(91 \pm 8.8 \%$ for KA and $100 \pm 13 \%$ for ATPA). The peak increase in mEPSC frequency in response to KA and ATPA was of comparable size, suggesting that GluK1 subunit containing receptors can fully account for KAR regulation of transmission at this synapse without additional (GluK1 lacking) KAR populations involved.

Finally, ACET had no effect on mEPSCs in P4-P6 CeA in slices that were preincubated in presence of pertussis toxin (PTX), a selective inhibitor of the Goi/o signalling (mEPSC frequency in ACET, $108 \pm$ $17 \%$ of control; Figure $5 \mathrm{E}$ ). The incubation procedure itself had no effect on the regulation of transmission by KARs, as ACET application resulted in significant depression of mEPSC frequency in slices incubated under control conditions (72 $\pm 12 \%, p<0.05$, paired t-test). Together, these data indicate that GluK1-subunit containing KARs upregulate glutamate release at immature BLA-CeA synapses via a G-protein coupled signalling mechanism.

\section{GluK1 expression in the BLA influences development of glutamatergic connections to CeA}

Immature-type KAR activity is proposed to be critical for development and fine-tuning of the glutamatergic synapses (Vesikansa et al., 2007; 2012; Orav et al., 2017). To investigate the significance of the early KAR activity on circuit wiring in the amygdala, we focused on studying the LA-CeA connections. To this end, we generated a conditional (floxed) mouse model for GluK1 (GriK1 (KO), which allowed us to inactivate GluK1 expression selectively in the neonate BLA in vivo with local injection of eGFP-Cre encoding AAV virus at P2-P4. Consequences on glutamatergic connectivity were investigated with patch clamp recordings of mEPSCs from acute slices at P21, followed by post hoc morphological analysis of the recorded biocytin filled neurons. The recordings were made from neurons in the centrolateral (CeLA) part of the CeA, which, in contrast to $४ \mathrm{P} 16$, can be clearly visualized at this developmental stage in acute slices. The viral transduction covered $59 \pm$ $7 \%$ of BLA cells at P21 (figure $6 \mathrm{~A}$ ), based on green fluorescence signal in DAPI labeled cells (Figure 6A). In slices from eGFP-Cre-injected GluK1 cKO mice, mEPSC frequency in CeLA neurons was significantly lower as compared to eGFP-injected controls ( $45 \pm 8 \%$ of eGFP control, $p<0.05$, ANOVA; Figure 6B). Post hoc morphological analysis indicated that the loss of functional glutamatergic inputs was associated with a significant reduction in the spine density $(61 \pm 12 \%$ of eGFP control, $p<0.05$, ANOVA ; Figure $6 \mathrm{C}$ ) and interestingly, lower dendritic length and branching (54 $\pm 7 \%$ of eGFP control, $p<0.01$, ANOVA ; Figure 6D).

To investigate the consequences of targeted GluK1 knockout on amygdala excitability, we recorded spontaneous EPSCs and IPSCs from CeLA. Regular firing (RF) and late firing (LF) neuron populations were analysed separately given the recent data suggesting that overexpression of KARs has dissimilar effects on glutamatergic inputs to these neurons (Arora et al., 2017). We found that developmental loss of GluK1 specifically affected glutamatergic inputs to the LF cell population, where SEPSC frequency was significantly lower in the slices from eGFP-Cre injected mice as compared to eGFP controls (sEPSC frequency, $56 \pm 5 \%, p<0.05$, ANOVA; Figure 6E). There was no significant difference in the sEPSCs between the groups in the RF cells (eGFP-Cre, $95 \pm 14 \%$ of 
control). sIPSC frequency was slightly but not significantly higher in RF neurons in eGFP-Cre injected group as compared to controls (LF, $115 \pm 25 \%$; RF, $173 \pm 32 \%, p=0.07$, ANOVA; Figure 6E).

These data suggested that loss of GluK1 impairs development of glutamatergic inputs to CeLA, leading to significant changes in the excitation-inhibition balance in the amygdala circuit $(p<0.05$, ANOVA on ranks, for sEPSC/sIPSC ratio between eGFP-Cre and eGFP groups in LF neurons). To confirm that this effect was indeed due to the early endogenous activity of GluK1 in the LA, we used lentiviral vectors to manipulate GluK1 expression in neonatal rats. Lentiviral shRNA and overexpression produce faster changes in gene expression as compared to AAV - Cre mediated inactivation of a floxed allele, allowing the consequences of P1-4 injection to be analysed already at P10-11. In addition, the injected lentiviruses produced a transduction ( $48 \pm 4 \%$ of neurons) that was spatially restricted to LA (Figure 7A).

In slices with local lentiviral expression of GluK1 shRNA in the LA, mEPSC frequency in CeA at P10P11 was significantly lower as compared to controls expressing a mock shRNA construct (38 $\pm 18 \%$, $p<0.05$, ANOVA; Figure 7B). Accordingly, GluK1 overexpression (oe) in the LA was associated with significantly higher mEPSC frequency in the CeA as compared to GFP expressing controls at P14 (188 $\pm 38 \%, p<0.05$,ANOVA; Figure 7C). Neither, GluK1 shRNA or overexpression had a significant effect on mEPSC amplitude (71 $\pm 12 \%$ and $91 \pm 11 \%$, respectively). Importantly, GluK1 oe in the LA recapitulated the tonic KAR dependent regulation of $\mathrm{mEPSC}$ frequency in the CeA at a developmental stage (P14) when this regulation was no longer observed at control or GFP expressing slices. Thus, in slices with LA-specific GluK1 oe, ACET application resulted in a significant decrease in the mEPSC frequency in CeA cells ( $73 \pm 11 \%$ of control, $p \varangle 0.05$, paired t-test), but had no effect in control (GFP expressing) slices (103 $\pm 7 \%$ of control) (Figure 7D). These results confirm that presynaptic GluK1 KARs, located in the axons of LA principal neurons, regulate glutamatergic transmission to CeA.

The ongoing GluK1 dependent facilitation of transmission contributes to the observed increase in the basal mEPSC frequency in GluK1 oe slices. In addition, morphological analysis of the CeA neurons indicated that the number of dendritic intersections in both apical and distal dendrites was significantly higher in GluK1 oe slices as compared to controls (total dendritic length in GluK1 oe slices, $200 \pm 22 \%$ of GFP, $p<0.01$, ANOVA; Figure 7E). In contrast, no significant differences in the density of dendritic spines were detected (mean density of spines in GluK1 oe slices, $116 \pm 7 \%$ of GFP control; Figure 7F).

Together, these data indicate that developmental manipulation of GluK1 expression in the LA results in lasting changes in connectivity between LA and CeA and support that presynaptic GluK1 subunit containing KARs are required for appropriate development of intrinsic glutamatergic connections in the amygdala. 


\section{Discussion}

Given the importance of the amygdala in several developmentally originating neuropsychiatric disorders, it is surprising how little is understood on the mechanisms that govern formation and refinement of the synaptic circuitry in the amygdala. In particular, very little is known on the development of the projections from the BLA to CeA, critical elements in the neural circuits mediating fear and anxiety (Duvarci and Pare 2014; Herry and Johansen 2014). Here we show that functional glutamatergic connections to CeA develop rapidly during the first 10-11 postnatal days in rats, before the external cortical inputs to amygdala emerge (Bouwmeester et al. 2002; Arruda Carvalho et al., 2017). Further, we demonstrate that during the time of intense synaptogenesis, transmission to CeA is strongly regulated by physiological activity of presynaptic KARs, which is critical for appropriate development of the LA-CeA connections.

Histological and functional evidence indicate that maturation of the intrinsic and extrinsic connectivity in the rodent BLA occurs postnatally, being completed around P21-P28 (Nair \& Gonzalez-Lima 1999; M orys et al., 1998; Bosch and Ehrlich 2015; Ryan et al., 2016; Arruda - Carvalho et al., 2017), in parallel with emergence of amygdala - dependent forms of associative emotional learning (e.g. Landers \& Sullivan 2012; Hartley and Lee 2015; Deal et al., 2016). Consistently, we found that spine density at BLA neurons increased gradually during the first three postnatal weeks while the density of functional inputs, assessed by mEPSC frequency, stabilized after the second postnatal week. Interestingly, glutamatergic inputs to the CeA reached maturity earlier as compared to BLA, the mEPSC frequency stabilizing already at P10-11 and spine density at around P14-16. Based on tracing studies, the external inputs to amygdala develop gradually from P7 onwards, most cortical inputs arriving only after the second postnatal week (Bouwmeester et al. 2002; Arruda Carvalho et al., 2017). However, CeA receives strong glutamatergic input from BLA (Pape and Pare, 2010; Sah et al., 2003), suggesting that rapid increase in mEPSC frequency between P5-P10 reflects mainly formation of the intrinsic amygdala circuits and specifically, development of the BLA - CeA connectivity. These data support that the local circuit in the amygdala is wired before the cortical inputs underlying behavior actuate.

Kainate receptors are highly expressed in the adult amygdala (Bettler et al., 1990; Li et al., 2001). However, no previous data on the expression and function of KARs during amygdala development exists. Our data show that the low-affinity subunits GluK1 and GluK2 and the high-affinity subunit GluK5 are strongly expressed in the BLA during the first postnatal week, when the glutamatergic synapses are rapidly developing. All the subunits were also detected in the central amygdala and in the intercalated neurons. The expression pattern of various KAR subunits in the newborn amygdala showed no evident cell-type specificity, thus giving little insight into their functions in the neonatal BLA circuitry. Yet, the finding that GluK1 expression was strongly downregulated during development, in parallel with maturation of synaptic connectivity, is reminiscent to hippocampus where this subunit has central role in regulating synaptic plasticity and formation of CA3-CA1 synaptic connections (Lauri et al., 2006; Vesikansa et al., 2012; Clarke et al., 2014; Orav et al., 2017). 
Intriguingly, during the first postnatal week corresponding to the developmental peak in expression of most KAR subunits, ionotropic activity of KARs was weak in the BLA. Contrary to the declining mRNA expression profile, KAR mediated inward currents were significantly increased during development in all amygdala nuclei studied. Instead, we found that tonic G-protein coupled signaling via GluK1 subunit containing KARs regulated glutamate release in a developmentally restricted manner. Our data thus supports that G-protein coupled 'non-canonical' signaling is a dominant mode of KAR activity during the time of intense synaptogenesis, while the emergence of ionotropic KARs correlates with circuit maturation (Marchal and Mulle, 2004).

In adult BLA, GluK1 KAR activity facilitates glutamate release (e.g. Arodianou-Anderjaska et al., 2012; Arora et al., 2018) indicating that presynaptic KARs are present in adult but are functionally distinct from the immature-type receptors that tonically inhibit release in these inputs. According to our results, the adult-type presynaptic KARs might be endogenously active in the juvenile (P14-16) LA but not in BA or CeA; however, previous studies using KAR antagonists with a broader subunit specificity (UBP302, UBP310) have detected endogenous KAR activity also in the adult BLA (Arodianou-Anderjaska et al., 2012; Arora et al., 2018). During first weeks of life, concentration of ambient glutamate is high (e.g. Hanson et al., 2019) and sufficient to activate high-affinity GluK1 subunit containing KARs (Lauri et al., 2006; Segerstråle et al., 2010). The developmental increase in glial glutamate uptake thus provides a plausible mechanism for the decline in the tonic KAR activity. Parallel changes in KAR subunit composition affecting subcellular localization and affinity of the receptors (e.g. Vesikansa et al., 2012) likely contribute to the switch from immature to adult type KAR activity. The previous findings showing coupling of GluK1 to G-proteins (Rutkowska-Wlodarczyk et al., 2015) and recapitulation of immature-type synaptic signaling by GluK1c overexpression (Vesikansa et al., 2012; present data) support the view that expression of GluK1 and in particular, the GluK1c splice variant, is central to the early metabotropic KAR activity. In addition, the high agonist affinity, permitting the tonic activation, depends on availability of subunits GluK4/5 as well as the auxiliary subunits NETO1/2 (reviewed by Lerma and M arquez, 2013).

Recently, it was demonstrated that overexpression of KAR subunit GluK4 enhances tonic KAR activity in the adult amygdala and leads to profound changes in the circuit excitability (Arora et al., 2018). Since the immature-type tonic KAR activity temporally coincided with rapid development of functional glutamatergic synapses in the amygdala, we presumed that the physiological role of this activity is to modulate developmental wiring of the amygdala circuitry. Consistently, local GluK1 knockdown in the LA during the time of rapid development of the BLA-CeA connectivity significantly impaired glutamatergic transmission to CeA later on in life. This effect was associated with changes in dendritic morphology in the CeLA target neurons, involving reduction in both, the spine density as well as size of the dendritic tree. Likewise, prolonging the developmental KAR activity via GluK1 overexpression resulted in an expansion of the dendritic tree of $\mathrm{CeA}$ neurons, consistent with the idea that KAR activity promotes both functional and morphological maturation of the amygdala neuronal networks. The changes in dendritic morphology likely contribute to the observed changes in glutamatergic drive. However, our data does not indicate whether KARs directly influence dendritic development or whether the morphological alterations resulted secondarily from the KAR dependent changes in glutamatergic transmission early in life. 
The endogenous KAR activity particularly affected glutamatergic inputs to the subpopulation of late firing neurons in the CeLA, which displayed significantly lower frequency of sEPSCs in preparations where GluK1 activity was silenced. Interestingly, data from the adult GluK4 overexpressing mice indicate that presynaptic KAR activity inhibits glutamate release in this pathway (Arora et al., 2018). Accordingly, loss of ongoing KAR dependent regulation of neurotransmitter release cannot explain the functional phenotype in GluK1 deficient amygdala in juvenile/adult stage. Rather, all the available data supports the view that loss of glutamatergic input to the LF neurons is a result of perturbed development of the synaptic connectivity in the absence of GluK1. Excitability of the LF (PKC- $\delta+)$ neurons in the CeA controls anxiety - like behaviors in mice (Tye et al., 2011; Cai et al., 2014) suggesting that impaired early KAR activity, leading to altered excitatory drive to LF CeA neurons, might be a causative factor in developmentally originating anxiety disorders.

In summary, we have here characterized a physiological KAR mechanism regulating wiring of the intrinsic glutamatergic connectivity in the amygdala. The metabotropic KAR signaling operates during the time of intense synaptogenesis, before the onset of amygdala-dependent behaviors and emergence of the cortical inputs. KARs have been implicated in CNS disorders related to dysfunction of the limbic areas, including mood and anxiety disorders, autism, schizophrenia, as well as epilepsy and stoke (Lerma \& Marquez, 2013; Jane et al., 2009). Indeed, KAR dependent modulation of the transmission from BLA to CeA is associated with aberrant amygdala dependent behaviors in adult mice, resembling the human endophenotypes associated with autism and schizophrenia (Arora et al., 2018). Our data indicate that the KAR-dependent circuit remodeling physiologically operates in the developing brain, and support the idea that KAR malfunction during circuit development might contribute to aberrant connectivity that may predispose to neurological disorders later on in life.

\section{Acknowledgements}

We thank Prof. Andreas Lüthi and his group members for their expert help with amygdala slice electrophysiology. Kirsi Kolehmainen, Erja Huttu and Outi Kostia are acknowledged for the outstanding technical help. This study was financially supported by the Academy of Finland, Sigrid Juselius Foundation and Jane and Aatos Erkko foundation.

\section{Author contributions}

M.R., J.E., A.S. and J.H. performed research and analyzed the data, A.P., J.M .P., M.R. and S.E.L. designed research, S.E.L. wrote the paper.

\section{Declaration of interests}

The authors declare no competing interests. 


\section{References}

Aroniadou-Anderjaska, V., Pidoplichko, V.I., Figueiredo, T.H., Almeida-Suhett, C.P., Prager, E.M., Braga, M .F. (2012). Presynaptic facilitation of glutamate release in the basolateral amygdala: a mechanism for the anxiogenic and seizurogenic function of GluK1 receptors. Neuroscience 221, 157-69.

Arora, V., Pecoraro, V., Aller, M.I., Román, C., Paternain, A.V., and Lerma, J. (2018). Increased Grik4 Gene Dosage Causes Imbalanced Circuit Output and Human Disease-Related Behaviors. Cell Rep. 23, 3827-3838.

Arruda-Carvalho, M., Wu, W.C., Cummings, K.A., and Clem, R.L. (2017). Optogenetic Examination of Prefrontal-Amygdala Synaptic Development. J Neurosci. 37, 2976-2985.

Berdel, B., Morys, J., and Maciejewska, B. (1997). Neuronal changes in the basolateral complex during development of the rat's amygdala. Int. J. Dev. Neurosci. 15, 755-765.

Bettler, B., Boulter, J., Hermans-Borgmeyer, I., O'Shea-Greenfield, A., Deneris, E.S., M oll, C., Borgmeyer, U., Hollmann, M ., and Heinemann, S. (1990). Cloning of a novel glutamatereceptor subunit, GluR5: expression in the nervous system during development. Neuron 5, 583-595.

Bosch, D., and Ehrlich, I. (2015). Postnatal maturation of GABAergic modulation of sensory inputs onto lateral amygdala principal neurons. J Physiol. 593, 4387-409.

Bouwmeester, H., Smits, K., and Van Ree, J.M . (2002). Neonatal development of projections to the basolateral amygdala from prefrontal and thalamic structures in rat. J Comp Neurol 450, 241-255.

Cai, H., Haubensak, W., Anthony, T.E., Anderson, D.J. (2014) Central amygdala PKC- $\delta+$ neurons mediate the influence of multiple anorexigenic signals. Nature Neurosci 17, 1240-1248.

Chang, S., and De Camilli, P. (2001). Glutamate regulates actin-based motility in axonal filopodia. Nat Neurosci. 4, 787-93.

Clarke, V.R., M olchanova, S.M ., Hirvonen, T., Taira, T., and Lauri, S.E. (2014). Activity-dependent upregulation of presynaptic kainate receptors at immature CA3-CA1 synapses. J Neurosci. 34, 16902-16.

Dargan, S.L., Clarke, V.R., Alushin, G.M., Sherwood, J.L., Nisticò, R., Bortolotto, Z.A., Ogden, A.M., Bleakman, D., Doherty, A.J., Lodge, D., M ayer, M.L., et al. (2009). ACET is a highly potent and specific kainate receptor antagonist: Characterisation and effects on hippocampal mossy fibre function. Neuropharmacology 56, 12130.

Deal, A.L., Erickson, K.J., Shiers, S.I., and Burman, M.A. (2016). Limbic system development underlies the emergence of classical fear conditioning during the third and fourth weeks of life in the rat. Behav Neurosci. $130,212-30$.

Donato, F., Rompani, S.B., and Caroni, P. (2013). Parvalbumin-expressing basket-cell network plasticity induced by experience regulates adult learning. Nature 504, 272-6.

Duvarci, S., and Pare, D. (2014). Amygdala microcircuits controlling learned fear. Neuron 82, 966-980.

Foehring, R.C., and Scroggs, R.S. (1994). Multiple high-threshold calcium currents in acutely isolated rat amygdaloid pyramidal cells. J Neurophysiol. 71, 433-6.

Hanson, E., Armbruster, M., Lau, L.A., Sommer, M.E., Klaft, Z.J., Swanger, S.A., Traynelis, S.F., M oss, S.J., Noubary, F., Chadchankar, J., Dulla, C.G. (2019). Tonic Activation of GluN2C/GluN2D-Containing NM DA Receptors by Ambient Glutamate Facilitates Cortical Interneuron M aturation. J Neurosci. 39(19), 3611-3626.

Hartley, C.A., and Lee, F.S. (2015). Sensitive periods in affective development: nonlinear maturation of fear learning. Neuropsychopharmacology 40, 50-60. 
Herry, C., and Johansen, J.P. (2014). Encoding of fear learning and memory in distributed neuronal circuits. Nat Neurosci. 17, 1644-54.

Ibarretxe, G., Perrais, D., Jaskolski, F., Vimeney, A., and M ulle, C. (2007). Fast regulation of axonal growth cone motility by electrical activity. J Neurosci 27, 7684-95.

Jane, D.E., Lodge, D., and Collingridge, G.L. (2009). Kainate receptors: pharmacology, function and therapeutic potential. Neuropharmacology 56, 90-113.

Joseph, D.J., Williams, D.J., and MacDermott, A.B. (2011) M odulation of neurite outgrowth by activation of calcium-permeable kainite receptors expressed by rat nociceptive-like dorsal root ganglion neurons. Dev Neurobiol 71, 818-835.

Keifer, O.P. Jr., Hurt, R.C., Ressler, K.J., Marvar, P.J . (2015) The Physiology of Fear: Reconceptualizing the Role of the Central Amygdala in Fear Learning. Physiology (Bethesda) 30(5), 389-401.

Ko, S., Zhao, M.G., Toyoda, H., Qiu, C.S., and Zhuo, M. (2005). Altered behavioral responses to noxious stimuli and fear in glutamate receptor 5 (GluR5)- or GluR6-deficient mice. J Neurosci. 25, 977-84.

Landers, M.S., and Sullivan, R.M. (2012). The development and neurobiology of infant attachment and fear. Dev Neurosci 34, 101-114.

Lanore, F., Labrousse, V.F., Szabo, Z., Normand, E., Blanchet, C., and Mulle, C. (2012). Deficits in morphofunctional maturation of hippocampal mossy fiber synapses in a mouse model of intellectual disability. J Neurosci 32, 17882-93.

Lauri, S.E., Vesikansa, A., Segerstråle, M., M aingret, F., M ulle, C., Collingridge, G., Isaac, J. and Taira, T. (2006). Functional maturation of CA1 synapses involves activity-dependent loss of tonic kainate receptor-mediated inhibition of glutamate release. Neuron 50, 415-29.

Lauri, S.E., Segerstråle, M., Vesikansa, A., M aingret, F., M ulle, C., Collingridge, G.L., Isaac, J.T., and Taira, T. (2005). Endogenous activation of kainate receptors regulates glutamate release and network activity in the developing hippocampus. J Neurosci 25, 4473-84.

Lerma, J., and M arques, J.M. (2013). Kainate receptors in health and disease. Neuron 80, 292-311.

Li, H., Chen, A., Xing, G., Wei, M.L., and Rogawski, M.A. (2001). Kainate receptor-mediated heterosynaptic facilitation in the amygdala. Nat Neurosci. 4, 612-20.

Li, H., Penzo, M.A., Taniguchi, H., Kopec, C.D., Huang, Z.J., and Li B. (2013). Experience-dependent modification of a central amygdala fear circuit. Nat. Neurosci. 16, 332-339.

Marchal, C., and Mulle, C. (2004). Postnatal maturation of mossy fibre excitatory transmission in mouse CA3 pyramidal cells: a potential role for kainate receptors. J Physiol 561, 27-37.

M arques, J.M ., Rodrigues, R.J., Valbuena, S., Rozas, J.L., Selak, S., Marin, P., Aller, M .I., and Lerma, J. (2013). CRM P2 tethers kainate receptor activity to cytoskeleton dynamics during neuronal maturation. J Neurosci 33, 18298-310.

Mizukawa, K., Tseng, I.M., Otsuka, N. (1998). Quantitative electron microscopic analysis of postnatal development of zinc-positive nerve endings in the rat amygdala using Timm's sulphide silver technique. Brain Res Dev Brain Res. 50, 197-203.

M orys, J., Berdel, B., Jagalska-M ajewska, H., and Luczynska, A. (1999). The basolateral amygdaloid complex-its development, morphology and functions. Folia M orphol (Warsz). 58, 29-46.

Nair, H.P., and Gonzalez-Lima, F. (1999). Extinction of behavior in infant rats: development of functional coupling between septal, hippocampal, and ventral tegmental regions. J Neurosci. 19, 8646-55. 
Orav, E., Atanasova, T., Shintyapina, A., Kesaf, S., Kokko, M., Partanen, J., Taira, T., and Lauri, S.E. (2017). NETO1 Guides Development of Glutamatergic Connectivity in the Hippocampus by Regulating Axonal Kainate Receptors. eNeuro 4(3).

Pape, H.C. and Pare, D. (2010). Plastic synaptic networks of the amygdala for the acquisition, expression, and extinction of conditioned fear. Physiol Rev. 90, 419-63.

Pitkänen, A., Savander, V. and LeDoux, J.E. (1997). Organization of intra-amygdaloid circuitries in the rat: an emerging framework for understanding functions of the amygdala. Trends Neurosci. 20, 517-523.

Ruiz, A., Sachidhanandam, S., Utvik, J.K., Coussen, F., Mulle, C. (2005). Distinct subunits in heteromeric kainate receptors mediate ionotropic and metabotropic function at hippocampal mossy fiber synapses. J Neurosci. 25(50), 11710-8.

Rutkowska-Wlodarczyk, I., Aller, M.I., Valbuena, S., Bologna, J.C., Prézeau, L., and Lerma, J. (2015). A proteomic analysis reveals the interaction of GluK1 ionotropic kainate receptor subunits with Go proteins. J Neurosci. 35, 5171-9.

Ryan, S.J., Ehrlich, D.E., and Rainnie, D.G. (2016). Morphology and dendritic maturation of developing principal neurons in the rat basolateral amygdala. Brain Struct Funct. 221, 839-54.

Sah, P., Faber, E.S., Lopez De Armentia, M., and Power, J. (2003). The amygdaloid complex: anatomy and physiology. Physiol Rev 83, 803-834.

Sallert, M ., Malkki, H., Segerstråle, M., Taira, T., and Lauri, S.E. (2007). Effects of the kainate receptor agonist ATPA on glutamatergic synaptic transmission and plasticity during early postnatal development. Neuropharmacology 52, 1354-65.

Sakha, P., Vesikansa, A., Orav, E., Heikkinen, J., Kukko-Lukjanov, T.K., Shintyapina, A., Franssila, S., Jokinen, V., Huttunen, H.J., and Lauri, S.E. (2016). Axonal Kainate Receptors Modulate the Strength of Efferent Connectivity by Regulating Presynaptic Differentiation. Front Cell Neurosci. 10, 3.

Segerstråle, M., Juuri, J., Lanore, F., Piepponen, P., Lauri, S.E., Mulle, C., Taira, T. (2010) High firing rate of neonatal hippocampal interneurons is caused by attenuation of afterhyperpolarizing potassium currents by tonically active kainate receptors. J Neurosci. 30(19), 6507-14.

Shin, R-M., Tully, K., Li, Y., Cho, J.H., Higuchi, M., Suhara, T., and Bolshakov, V.Y. (2010). Hierarchical order of coexisting pre- and postsynaptic forms of long-term potentiation at synapses in amygdala. PNAS 107, 19073.

Tamamaki, N., Yanagawa, Y., Tomioka, R., M iyazaki, J., Obata, K., and Kaneko, T. (2003). Green fluorescent protein expression and colocalization with calretinin, parvalbumin, and somatostatin in the GAD67-GFP knock-in mouse. J. Comp. Neurol. 467, 60-79.

Tashiro, A., Dunaevsky, A., Blazeski, R., Mason, C.A. and Yuste, R. (2003). Bidirectional regulation of hippocampal mossy fiber filopodial motility by kainate receptors: A two-step model of synaptogenesis. Neuron 38, 773.

Tottenham, N., and Sheridan, M.A. (2010). A review of adversity, the amygdala and the hippocampus: a consideration of developmental timing. Front Hum Neurosci. 3, 68.

Tye, K.M., Prakash, R., Kim, S.Y., Fenno, L.E., Grosenick, L., Zarabi, H., Thompson, K.R., Gradinaru, V., Ramakrishnan, C., Deisseroth, K. (2011). Amygdala circuitry mediating reversible and bidirectional control of anxiety. Nature 471, 358. 
Vesikansa, A., Sakha, P., Kuja-Panula, J., M olchanova, S., Rivera, C., Huttunen, H.J., Rauvala, H., Taira, T., and Lauri, S.E. (2012). Expression of GluK1c underlies the developmental switch in presynaptic kainate receptor function. Sci Rep 2, 310.

Vesikansa, A., Sallert, M., Taira, T., and Lauri, S.E. (2007). Activation of kainate receptors controls the number of functional glutamatergic synapses in the area CA1 of rat hippocampus. J Physiol. 583, 145-57

Wilkinson, D.G., and Green, J. (1990). In situ hybridization and the three-dimensional construction of serial sections. In Postimplantation Mammalian Embryos, Copp, A.J., Cockroft, D.L. ed. (IRL Press, Oxford)

Wyeth, M.S., Pelkey, K.A., Petralia, R.S., Salter, M.W., M clnnes, R.R., M cBain, C.J. (2014) Neto auxiliary protein interactions regulate kainate and NMDA receptor subunit localization at mossy fiber-CA3 pyramidal cell synapses. J Neurosci. 34(2), 622-8. 


\section{Figure legends}

\section{Figure 1. Kainate receptors are highly expressed in the amygdala during the first postnatal week}

A. The predominant KAR subunits expressed in the newborn BLA are GluK1, GluK2 and GluK5 and the auxiliary subunit NETO2. RT-aqPCR data on GluK1-5, Neto1 and Neto2 mRNA expression in the BLA at P4 ( $n=3-4$ / group).

B. RT-qPCR analysis of GluK1-5, Neto1 and Neto2 mRNA expression in the BLA at different stages of development, expressed as a percentage of the level at P4 ( $n=3-10$ / group). GluK1 expression is strongly downregulated during early postnatal development. $* p<0.05, * * p<0.001$ as compared to P4.

C. Western blot from neonatal (P4 and P14) BLA, using antibodies against GluK2/3 and GluK5. Betaactin was used as a loading control. GluK2 and GluK5 protein was clearly detected in the BLA both at P4 and P14. Quantification of the signal indicates no significant developmental changes in the expression level.

D. Cell-type specific expression pattern of KAR subunits in the amygdala during early postnatal development. Example images showing ISH staining (red) with antisense RNA probes against GluK1, GluK2 and GluK5 in the P4 mouse amygdala, in GAD67GFP positive (green) and negative (blue DAPI stain) cells. Scale bar, $100 \mu \mathrm{m}$.

E. Pooled data on the integrated density of the ISH signal, normalized to the number of cell bodies (identified by DAPI staining) within the analyzed region at P4 and P14. CA3 area of the hippocampus is analyzed as a reference. GluK1 mRNA expression is strongly downregulated in all amygdala subnuclei during first weeks of postnatal development. LA, Lateral amygdala; BA Basal Amygdala; CeA Central amygdala; ITC Intercalated cells. ( $n=3-4$ / group). *p $<0.05, * * p$ $<0.001$.

\section{Figure 2. Development of glutamatergic synaptic connectivity in the amygdala}

A. Example traces of action-potential independent glutamatergic events (mEPSCs), recorded from BA and CeA neurons at different stages of development (P5, P10 and P15).

B. Pooled data of mEPSC frequency in amygdala subnuclei at different stages of development ( $n=7$ 11 / group). The mEPSC frequency increases with a different developmental time course in CeA as compared to BA and LA. $* p<0.05, * * p<0.001$.

D. Confocal images illustrating dendritic spines in biocytin filled neurons from LA, Ba and CeA at P5, P10, P15 and P21

E. Pooled data on spine density in LA, BA and CeA neurons at difference stages of development. Data is obtained from 8-11 dendrites / group. * $p<0.05 ; * * p<0.001$. 
Figure 3. Functional map of ionotropic KAR activity in the amygdala during the first postnatal week

A. Example traces illustrating inward currents in response to application of $2 \mu \mathrm{M}$ kainate (KA) in the presence of blockers for AM PA, NM DA and GABA-A receptors, in LA, BA and CeA neurons at P4-6 and P14-16. $33 \mathrm{mM} \mathrm{KCl}$ was applied as a positive control. In the neonatal BLA, no KA induced currents are detected while a clear current is induced under similar conditions at P14P16.

B. Pooled data on the effect of $2 \mu \mathrm{M}$ kainate on holding current in LA, BA and CeA neurons at two different stages of development (P4-6 and P14-16; LA $n=10$ and 13; BA: $n=14$ and 12, CeA $n=12$ and 12 , respectively).

C. Example traces showing that application of $500 \mathrm{nM}$ of domoate (DA) induced no current in neonate LA neurons, while a small inward current was detected in BA (P4-6). The recordings were made in the presence of blockers for AM PA, NM DA and GABA-A receptors.

D. Pooled data comparing the effect of or $2 \mu M$ kainate $(L A n=10, B A n=14$ ) and $500 n M$ domoate (LA: $n=10 ; B A: n=9$ ) on holding current in neonatal LA and $B A$ neurons.

\section{Figure 4. KARs regulate glutamatergic inputs to BA and CeA during the first postnatal week}

A. KAR antagonism does not affect action-potential independent glutamatergic events (mEPSCs) to LA during the first postnatal week. Example traces (P5) from the time points indicated (1-3) and time course plot of averaged data ( \pm s.e.m.) illustrating little or no effect of ACET ( $200 \mathrm{nM}$ ) on mEPSC frequency in LA at P4-7 and a small depression at P14-16. The graphs on the right show the mEPSC frequency under control conditions (1), in the presence of ACET (2), and after wash-out of the drug (3), in individual experiments at two different stages of development (P47 and P14-16; $n=7$ and 6, respectively). $* p<0.05$.

B. Similar data for recordings in the BA. In newborn BA, ACET application reversibly increases mEPSC frequency $(n=9)$. This effect is no longer observed at P14-P16 $(n=6){ }^{*} p<0.05$.

C. Similar data for recordings in the CeA. In the first week of life (P4-6; $n=9)$ but not at P9-11 $(n=6)$, ACET application leads to robust depression of mEPSC frequency. $* * p<0.01$.

Figure 5. Transmission at immature BLA-CeA synapses is tonically facilitated by presynaptic Gprotein coupled KARs.

A. KAR antagonism leads to reversible depression of glutamatergic transmission from to BLA-CeA during first postnatal week. Example traces of EPSCs, recorded from CeA neurons at P5 in response to paired-pulse stimulation of the $L A$, under control conditions and in the presence of $200 \mathrm{nM}$ ACET. Pooled data ( \pm s.e.m.) showing that ACET application is associated with a reduction in the EPSC amplitude and an increase in paired pulse ratio. $n=9$; ** $p<0.001$.

B. Postsynaptic KARs do not contribute to transmission at immature BLA-CeA synapses. Similar data as in A, showing that the AM PA receptor antagonist GYKI53655 fully blocks the EPSC. $n=$ 8; $p<0.001$. 
C. Example traces from the time points indicated (1-3) and time course plot (average \pm s.e.m.) depicting a transient increase mEPSC frequency in response to application of KA (500 nM). The graphs show mEPSC frequency under control conditions (1), in the presence of KA (2), and after wash-out of the drug (3) in individual cells in CeA (P4-6). $n=7 ; * p<0.05$.

D. Application of the GluK1 selective agonist ATPA leads to an increase in mEPSCs frequency, similar to that observed in response to $500 \mathrm{nM} \mathrm{KA}$. Example traces and pooled data as in $\mathrm{C} . \mathrm{n}=$ $6 ; * p<0.05$.

E. The tonic KAR activity regulating glutamatergic transmission to CeA acts via a G-protein dependent mechanism. The effect of ACET on mEPSC frequency is fully blocked in slices that are pre-incubated in the presence pertussis toxin (PTX; $=5$ ), but not in SHAM incubated controls $(n=5) . * p<0.05$.

Figure 6.Local inactivation of GluK1 in the basolateral amygdala (BLA) in a cKO mouse model perturbs development of glutamatergic projections to $\mathrm{CeA}$

A. Image illustrating the eGFP fluorescence in the BLA of GluK1 CKO mice (P21), after in vivo AAVeGFP virus injection at P2. The viral transduction was observed in $59 \pm 7 \%$ of the DAPI labeled cell bodies (blue; inset).

B. Example traces and pooled data showing that GluK1 knockdown in the BLA results in lower mEPSC frequency in the CeLA as compared to controls. AAV viruses encoding for eGFP-Cre of eGFP (control) were injected to the BLA at P2-4, and mEPSCs were recorded from the CeLA in acute slices at P21. $\mathrm{n}=10-12 ; * \mathrm{p}<0.05$.

C. post hoc morphological characterization of the biocytin filled CeLA neurons (P21). Analysis of dendritic spines was significantly reduced following GluK1 inactivation (eGFP-Cre, $n=9$; eGFP $\mathrm{n}=9$ ). $* * \mathrm{p}<0.01$. Scale bar, $5 \mu \mathrm{m}$

D. Sholl analysis of the recorded CeLA neurons indicate that number of dendritic intersections and the total dendritic length is significantly lower in eGFP-Cre infected slices as compared to controls. Pooled data (eGFP-Cre, $n=11$; eGFP $n=10$ ) and confocal images ( $z$-stack) illustrating the morphology of the dendritic tree. ${ }^{* *} p<0.01$. Scale bar, $50 \mu \mathrm{m}$

E. Example traces of firing pattern of late-firing (LF) and regular-firing (RF) neurons in CeA (P21) in response to depolarizing current pulses and recordings of spontaneous IPSCS and EPSCS under conditions where the sIPSCS are seen as outward currents and the sEPSCS were directed inwardly. sEPSC frequency was reduced in LF neurons in CeA in animals infected with eGFP-Cre at P2-4, as compared to eGFP-Cre infected controls. Pooled data on frequencies of sEPSCs and sIPSCs in RF and LF neurons in CeA ( $n=12$ for both groups, * $p<0.05$ ).

Figure 7. Local genetic manipulation of GluK1 expression in the LA perturbs development of the LA - CeA connections

A. Image showing local GFP expression in the LA at P11, after in vivo injection of GluK1 shRNA - GFP encoding lentivirus at P5. The inset panel shows a magnified image illustrating eGFP expression on average of $48 \pm 4 \%$ of DAPI labeled cells (blue).

B. Example traces and pooled data showing that shRNA mediated GluK1 knockdown in the LA results in lower mEPSC frequency in the CeA as compared to controls. GluK1 shRNA encoding 
lentivirus or mock lentivirus was injected to $L A$ at P5-6 and the recordings were made from CeA neurons at P10-11. (GFP; $n=6$; GluK1-shRNA: $n=5 * p<0.05$ ).

C. Slices with GluK1 overexpression (GluK1 oe) in the LA show a significantly higher mEPSC frequency in the CeA as compared to controls (GFP). In vivo transduction was done at P6-9 and recordings were made at P14-15. GluK1 oe, $n=14$, GFP $n=8 ; * p<0.05$.

D. GluK1 overexpression (GluK1 oe) in the LA recapitulates the developmental phenotype of presynaptic KAR activity. Example traces from the time points indicated (1-3) and time course plots of pooled data illustrate that in GluK1 oe slices, ACET application causes a significant decrease in mEPSC frequency in the CeA neurons $(n=5, p<0.05)$. At this developmental stage (P14-15), ACET has no effect on mEPSCs in control (GFP infected) slices $(n=5)$. Graphs on the right show mEPSC frequency under control conditions (1), in the presence of KA (2), and after wash-out of the drug ( 3 ) in individual cells. $* p<0.05$, paired t-test.

E. GluK1 oe results in an increase in dendritic length and branching. Sholl analysis of the biocytin filled CeA neurons indicate that number of dendritic intersections and the total dendritic length is significantly increased in slices with GluK1 oe in the LA. Pooled data (GluK1 oe, n= 6 ; GFP $n=7$ ) and confocal images ( $\mathrm{z}$-stack) illustrating the morphology of the dendritic tree. $* * p<0.01$. Scale bar, $50 \mu \mathrm{m}$.

F. GluK1 oe does not influence the density of dendritic spines in CeA neurons. Pooled data of the mean density of dendritic spines (GluK1 oe $n=7 ; G F P, n=9$ ). Example images shown on the right. Scale bar, $5 \mu \mathrm{m}$. 


\section{Materials and Methods}

\section{Animals}

Male and female Wistar rats (P4-P21) were used in most experiments. Heterozygous Grik1tmla(KOM P)M bp mice in C57BL/6N background were obtained from KOM P repository (UC

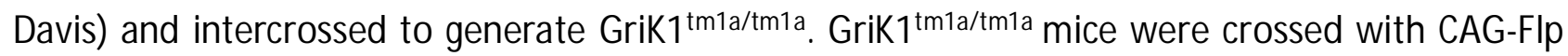
transgenic line to produce a floxed conditional allele (tm1c). Progeny homozygous for the tm1c allele (GriK1 tmlc/tmlc) was used for further breedings and experiments. Loss of GluK1 mRNA expression after AAV-Cre injection was validated using qPCR and loss of function was confirmed with electrophysiologial analysis (Supplementary Figure S1). All experiments were done in accordance with the guidelines given by the ethics committee for animal research at the University of Helsinki.

RNA extraction, CDNA synthesis and real-time PCR. The BLA was dissected from $500 \mu \mathrm{m}$ thick sections cut from the brain of Wistar rats as described (Lauri et al., 2006). Purification of total RNA, CDNA synthesis and the real-time quantitative PCR was carried out essentially as described (Orav et al., 2017) and using the primers listed in Table 1. All samples were analysed in triplicate. The initial copy numbers of a sample was obtained by relating the $\mathrm{Ct}$ of the sample to a standard curve plot. Relative quantification of gene expression at different developmental stages was analysed using standard $2^{\text {-ddCt }}$ method.

Table 1. Real-time PCR primers

\begin{tabular}{|l|l|l|l|}
\hline Target & Forward & Reverse & size bp \\
\hline GluK1 & ATGTGACGCAGAGGAACTGC & GCAGTTGAAGAATGGCAATCG & 126 \\
\hline GluK2 & GTTGTTACACAGCGGAACTG & CAGCTGAAGAATGCTATGGTG & 127 \\
\hline GluK3 & CATCGATTCCAAGGGCTACG & CGCCACCACTTCTCCTTCAT & 126 \\
\hline GluK4 & GACACCAAGGGCTATGGGAT & ACCACTTCCGCTTCAGAATC & 118 \\
\hline GluK5 & AGTACGGCACTATCCACGCT & CTCCTCTGTGCTCTTGACGA & 128 \\
\hline Neto1 & TCATAGAAGCTGCCCCAAGG & AAGCCAAAGGGTCCATCTCG & 118 \\
\hline Neto2 & TTGGAAGCTGCTCCTCGTC & TCCAAGTGATCAAACCGGCA & 93 \\
\hline GAPDH & CAGTGCCAGCCTCGTCTCATA & TGGTAACCAGGCGTCCGATA & 79 \\
\hline
\end{tabular}

Western blotting. Eight P4 rats and six P14 rats were used for measuring the protein levels of the GluK2/3, and GluK5 subunits in the BLA. BLA was dissected from $500 \mu \mathrm{m}$ thick brain sections and the tissue was sonicated in lysis buffer (1\% NP-40, $20 \mathrm{mM}$ Tris, pH 8.0, $137 \mathrm{nM} \mathrm{NaCl}, 10 \%$ glycerol, Phosphatase Inhibitor Cocktails; Upstate, Temecula, CA, USA). Cellular debris was removed by centrifugation. Protein concentrations were measured by a colorimetric DC Protein Assay (Bio-Rad, USA). $60 \mu \mathrm{g}$ of each sample from each brain region were used in the analysis in triplicate. Proteins were separated on 4-15\% M ini-Protean TGX Gel (Bio-Rad, USA) and transferred to PVDF membranes (M illipore). After blocking with 4\% non-fat dry milk in PBS for $1 \mathrm{~h}$, the membranes were incubated overnight at $4{ }^{\circ} \mathrm{C}$ with specific primary antibodies, diluted in $2 \%$ non-fat dry milk in PBS as follows: 
anti-GluR6/7 (GluK2/3), (1:2000; M illipore), KA2 (GluK5) (1:2000; M illipore), and anti-beta-actin (1:10000; Sigma-Aldrich), which was used as a loading control in all experiments. After washing in PBS-T, membranes were incubated with peroxidase-conjugated goat anti-rabbit (1:5000; Bio-Rad, USA) or goat anti-mouse (1:5000; Bio-Rad, USA) secondary antibodies (2\% non-fat dry milk in PBS; Ih at RT). After washing in PBS-T, blots were developed using enhanced chemiluminescence with Pierce ECL Western Blotting Substrate (Thermo Scientific). Intensity of the bands was analysed using ImageJ software and normalized relative to the beta-actin.

In situ hybridization (ISH). ISH was carried out on $5 \mu \mathrm{m}$ thick paraffin sections from rat and mouse (GAD67GFP; Tamamaki et al., 2003) brain as described (Wilkinson and Green, 1990). The digoxigenin (DIG)-labeled antisense and sense RNA probes against KAR subunits GluK1, GluK4, GluK5, Neto1 and Neto2 were as previously described (Vesikansa et al., 2012; Orav et al., 2017). GluK2 cDNA was amplified by PCR using the following primers: Forward GGATGTGATCAGTCTCAAGG, Reverse AGCCAGCAGAACATACATCC. The fragment (532 bp) was subcloned into pGEM -T vector (Promega). The plasmid was linearized by restriction digest and used as a template for in vitro transcription with DIG RNA Labeling kit (Roche Diagnostics).

TSA-Plus Cyanine3 / Fluo rescein System (Perkin Elmer) was used to visualize ISH signal, followed with a standard DAPI staining. In GAD67GFP mouse sections, the primary antibody against GFP (rabbit anti-GFP ab290, Abcam) was added after the ISH signal detection to amplify the GFP signal. Stained sections were imaged using Zeiss Axioimager M2 microscope with Axiocam HRc camera.

The specificity of reaction conditions was first tested in P14 rat hippocampal sections, to ensure specific staining with anti-sense probe and to control that there was no unspecific signal with the corresponding sense RNA probes (Vesikansa et al., 2012). The level of mRNA expression in the amygdala nuclei was quantified based on the optical density of the ISH signal within anatomically defined area, which was normalized against the quantity of cells (DAPI staining) using Image) software. mRNA expression level in hippocampal CA3 region was examined as a reference. For the histograms, data from rat and mouse sections have been pooled as no major differences in the expression pattern between the species were detected. At least 3 sections were analysed for each animal, and at least 3 animals were included in each group.

Electrophysiology. Acute parasagittal sections (300-400 $\mu \mathrm{m})$ were prepared from brains of neonatal

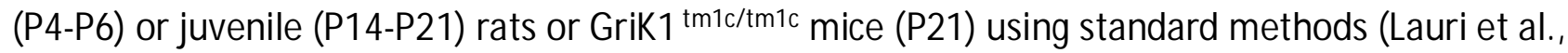
2006). After recovery, the slices were transferred to a submerged recording chamber and superfused with extracellular solution (ACSF) containing (mM): $124 \mathrm{NaCl}, 3 \mathrm{KCl}, 1.25 \mathrm{NaH}_{2} \mathrm{PO}_{4}, 1$ $\mathrm{MgSO}_{4}, 26 \mathrm{NaHCO}_{3}, 15 \mathrm{D}$-glucose, $2 \mathrm{CaCl}_{2} ; 5 \% \mathrm{CO}_{2} / 95 \% \mathrm{O}_{2}$, at $30^{\circ} \mathrm{C}$. Whole-cell patch clamp recordings were performed from $\mathrm{BLA}$ and $\mathrm{CeA}$ neurons under visual guidance using patch electrodes with resistance of 3-5 $\mathrm{M} \Omega$. Uncompensated series resistance (Rs) was monitored by measuring the peak amplitude of the fast whole-cell capacitance current in response to a $5 \mathrm{mV}$ step. Only experiments where Rs $<30 \mathrm{M} \Omega$, and with $<20 \%$ change in Rs during the experiment, were included in analysis.

Kainate and domoate induced currents were recorded in the presence of antagonists for AM PA, NMDA and GABA-A receptors (2 $\mu \mathrm{M}$ NBQX, $50 \mu \mathrm{M}$ D-(-)-2-amino-5-phosphonopentanoic acid (D- 
AP5) and $100 \mu \mathrm{M}$ picrotoxin (PiTX), respectively) using intracellular solution containing (in mm): 135 K-gluconate, 10 HEPES, 5 EGTA, $4 \mathrm{Mg}$-ATP, $0.5 \mathrm{Na}-\mathrm{GTP}, 2 \mathrm{KCl}$, and $2 \mathrm{Ca}(\mathrm{OH})_{2}(285 \mathrm{mOsm}), \mathrm{pH}$ 7.2. The agonists were applied using fast local application to the slice and washed out by fast local application of ASCF; following application of ACSF with $33 \mathrm{mM} \mathrm{KCl}$ was used as a positive control. Glutamatergic synaptic currents were recorded using Cs-based intracellular solution containing (in $\mathrm{mM}$ ): $130 \mathrm{CsM} \mathrm{eSO}_{4}$, 10 HEPES, 0.5 EGTA, 4 M g-ATP, 0.3 Na-GTP, 5 QX-314, 8 NaCl; $280 \pm 5$ mOsm (pH 7.2). For post-hoc morphological analysis, biocytin (0.4\%) was included in the intracellular solution in some of the recordings. Evoked EPSCS were recorded at a holding membrane potential of $-70 \mathrm{mV}$ in response to stimulation of $L A$ by a bipolar metal electrode. Recordings were performed in the presence of PiTX $(100 \mu \mathrm{M})$ D-AP5 $(50 \mu \mathrm{M})$. Data were collected and analyzed online using LTP software (Anderson and Collingridge, 2007; www.winltp.com). Spontaneous miniature EPSCS (mEPSCs) were recorded in the presence of TTX $(1 \mu \mathrm{M})$, and PiTX $(100 \mu \mathrm{M})$. mEPSCs were analyzed with M iniAnalysis 6.0.3 program (Synaptosoft Inc.). Events were verified visually, and events with amplitude less than three times the baseline rms noise level were rejected. For time-course plots, detected events were calculated in 120-s bins. Pertussis toxin (PTX) treatment was performed with acute slices at $37^{\circ} \mathrm{C}$ for 3-5 hours. In these experiments, slices were washed with $1 \mathrm{~mL}$ incubation solution containing (in mM): $105 \mathrm{NaCl}, 3 \mathrm{KCl}, 1 \mathrm{MgSO}_{4}, 3.75 \mathrm{NaH}_{2} \mathrm{PO}_{4}, 26 \mathrm{NaHCO}_{3}, 2 \mathrm{CaCl}_{2}, 15 \mathrm{D}$ glucose, and 25 HEPES ( $\mathrm{pH}=7.2$ ) with or without $5 \mu \mathrm{M} \mathrm{PTX}$, and placed into M illicell CM 0.4- $\mu \mathrm{m}$ membrane inserts (Millipore) with $1 \mathrm{~mL}$ of the above solution.

Spontaneous glutamatergic and GABAergic synaptic events (sEPSCs and sIPSCs) were recorded using intracellular solution containing (in $\mathrm{mM}$ ): $135 \mathrm{~K}$-gluconate, $10 \mathrm{HEPES}, 2 \mathrm{KCl}, 2 \mathrm{Ca}(\mathrm{OH}) 2,5 \mathrm{EGTA}, 4$ $\mathrm{Mg}$-ATP, and 0.5 Na-GTP. After obtaining whole cell access, the firing properties of the cell were identified by applying a current injections (600 ms, increments of 20 pA from -100 to 300 pA) in current clamp mode. Then the cell was voltage clamped to $-50 \mathrm{mV}$ for recording of spontaneous synaptic activity. AP threshold and delay were analyzed off-line.

For all the electrophysiological data, $n$ number refers to the number of recorded neurons, which in all datasets were collected from at least 3 (in most cases from at least 6) different animals. Data obtained from the genetically manipulated mice were analyzed by researcher blind to the type of virus infection.

Morphological analysis. For post hoc morphological characterization of biocytin filled neurons, slices were fixed overnight in a $4 \%$ paraformaldehyde $\left(4^{\circ} \mathrm{C}\right)$, after which they were washed with $0.01 \mathrm{M}$ phosphate-buffered saline (PBS) and permeabilized with $0.01 \mathrm{M}$ PBS $0.3 \%$ Triton-X 100 (Sigma-Aldrich) for $1.5 \mathrm{~h}$ at room temperature. Streptavidin Conjugate (1:500; A488; Life Technologies) was added to the permeabilization solution and incubated for $4 \mathrm{~h}$. PBS-washed slices were mounted onto slides and blind-coded for morphological analysis. Dendritic trees and dendritic spines were imaged using a LSM Zeiss 710 confocal microscope (Zeiss Plan Neofluar 20x/0.50 and alpha Plan146 Apochromat 63x/1.46 OilKorr M 27 objectives). Dendritic trees were imaged with resolution of 2.3 pixels/ $\mu \mathrm{m}$ and Z-stack interval of $1 \mu \mathrm{m}$. Spines were imaged with resolution of 15.17 pixels/ $\mu \mathrm{m}$ and Z-stack interval of $0.5 \mu \mathrm{m}$. Spine density was evaluated on the primary dendrites for P7-11 and on the secondary for P14-21. Actual spine detection was done using the NeuronStudio software to quantify spines in a Z-stack image. Verification of the spine 
detection was done manually. Values of spine density per cell were used for statistical analysis. Sholl analysis was performed on 2D maximal intensity images acquired from Z-stacks, using the Fiji ImageJ plugin. The number of intersections was estimated with $10 \mu \mathrm{m}$ bins, and values per cell were used for statistical analysis. Total dendritic length were measured from traced dendrites of each cell.

Viral transduction in vivo. Lentiviral vectors encoding epitope-tagged GluK1 were as described previously (Vesikansa et al., 2012). The shRNA against GluK1 (target sequence: CCTGGACATTATCAGTCTCAA) was subcloned to modified pLKO.1 vector where the puromycin resistance cassette was replaced with GFP under the synapsin-1 promoter (pLKO.1- syn1-EGFP). The lentiviral particles were produced in HEK293T cells and purified as described (Vesikansa et al., 2012). The efficacy of the lentiviral shRNA to suppress expression of GluK1 was validated in cultured DRG cells, where GluK1 is endogenously strongly expressed (Supplementary figure S2). Lentiviral particles were injected to the LA area of 4-5 day old rat pups (for shRNA) and 6-9 day old pups (for overexpression) under isoflurane anesthesia. The animals were placed onto stereotaxic frame, the skull was exposed and 2 or 3 small holes at each side were done using dental drill. 0.3-0.6 ml of lentiviral suspension was injected into LA region of amygdala. The stereotaxic coordinates for LA were recalculated in the respect to bregma - lambda distance and varied in the following range for P5-6: AP 1.2, 2.0, 2.8 (from bregma), ML 3.8-3.9, DV 3.6-3.8; and for P6-9: AP 2.0, 2.8 (from bregma), M L 4.5-4.6, DV 6-6.2. The wound was stitched and treated with bacibact (Orion Pharma, Finland), sutured and the pup was left to recover with the dam.

AAV serotype 8 vectors encoding for eGFP (pAAV.CMV.PI.EGFP.WPRE.bGH) and eGFP-Cre (pAAV.CM V.HI.eGFP-Cre.WPRE.SV40) were purchased from Addgene (catalog \#105530-AAV8 and 105545-AAV8, respectively). The AAV particles were injected to the BLA of neonatal (P1-4) GriK ${ }^{\mathrm{tm} 1 \mathrm{c} / \mathrm{tm} 1 \mathrm{c}}$ mice under anaesthesia in a stereotaxic frame as described above, except that the injection was done through the skin and skull using the following coordinates: AP 3.8 (from brain apex) ML 2.2, DV 2.2 .

Statistical analysis. Statistical analysis was done on raw (not normalized) data using Sigma Plot software. Shapiro-Wilk test was used to test for normal distribution and Student's paired two-tailed t-test, one-way ANOVA with Holm-Sidak post hoc comparison or one-way ANOVA on ranks (KruskalWallis with Dunn's method for pairwise comparison) was then used accordingly as indicated in the text. All the pooled data are given as mean \pm S.E.M. 


\section{Supplementary figures}

\section{S1. Validation of the GluK1 cKO mouse model}

A. RT-qPCR results showing loss of GluK1 mRNA expression in the hippocampus $(\mathrm{HC})$ of GluK $1^{\text {tmlc/tm1c }}$ mice 23 days after injection of AAV virus encoding for eGFP-Cre. Injection was done in 9 week old mice. The data represents the level of GluK1 mRNA expression in eGFP-Cre - injected $\mathrm{HC}$ as a percentage of the control (eGFP injected $\mathrm{HC}, \mathrm{n}=3$ for both groups) . $* p<0.05$, unpaired t-test.

B. Loss of GluK1 function in the LA following eGFP-Cre injection in the GluK1 ${ }^{\mathrm{tm} 1 \mathrm{c} / \mathrm{tm} 1 \mathrm{c}}$ mice . Example traces and pooled data illustrating ATPA $(1 \mu \mathrm{M})$ induced currents in LA neurons in slices obtained from control (eGFP injected) but not in eGFP-Cre injected GluK1 ${ }^{\text {tm1c/tm1c }}$ mice (eGFP-Cre: $n=4$, eGFP: $n=4$; ANOVA; $p<0.05$ ). eGFP or eGFP-Cre encoding AAV viruses were injected to the BLA of adult GriK1 ${ }^{\text {tm1c/m1c }}$ mice, acute slices were cut for electrophysiological analysis 21 days after injection. Agonist induced currents were recorded as described in the main article.

\section{S2. Validation of the GluK1 shRNA}

A. A western blot illustrating that the GluK1 shRNA strongly inhibits expression of GluK1-myc but not GluK2-myc or GluK3-myc in HEK293T cells.

B. RT-qPCR results showing that the lentiviral GluK1 shRNA construct blocks expression of endogenous GluK1 in dorsal root gangion (DRG) neurons within $48 \mathrm{~h}$ from infection.

C. Methods for the Supplementary data 
A
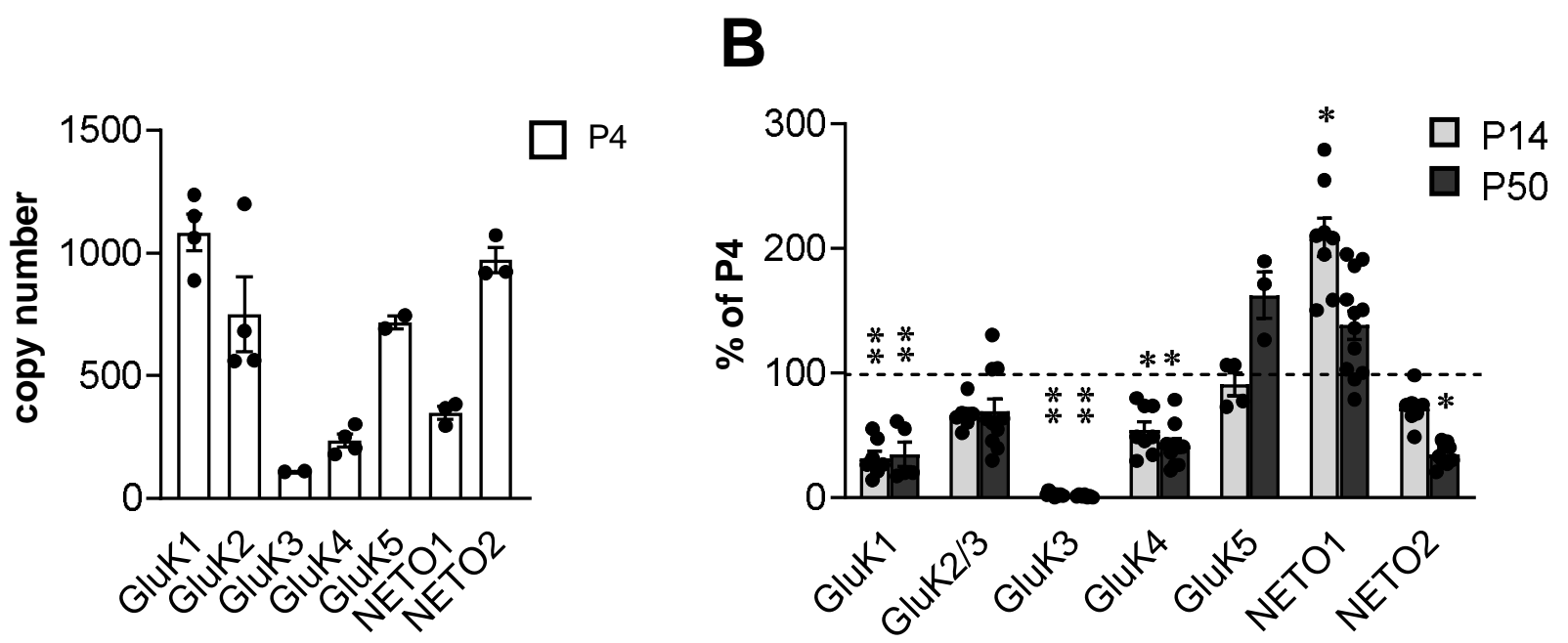

C

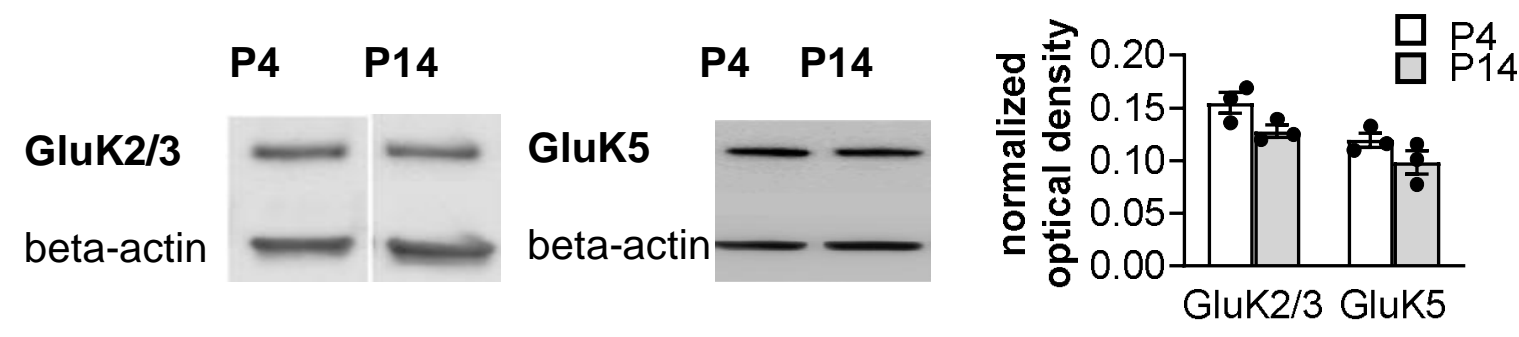

D

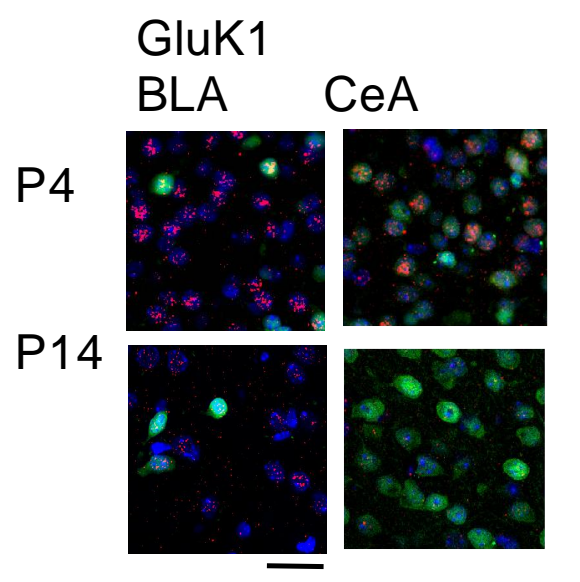

GluK2
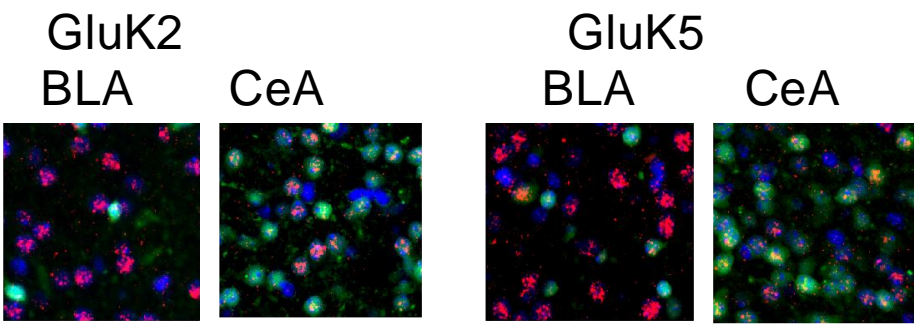

GluK
GAD67
DAPI

$\mathbf{E}$
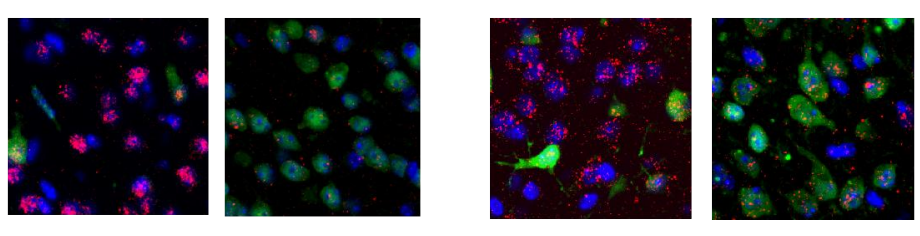

GluK2

GluK5
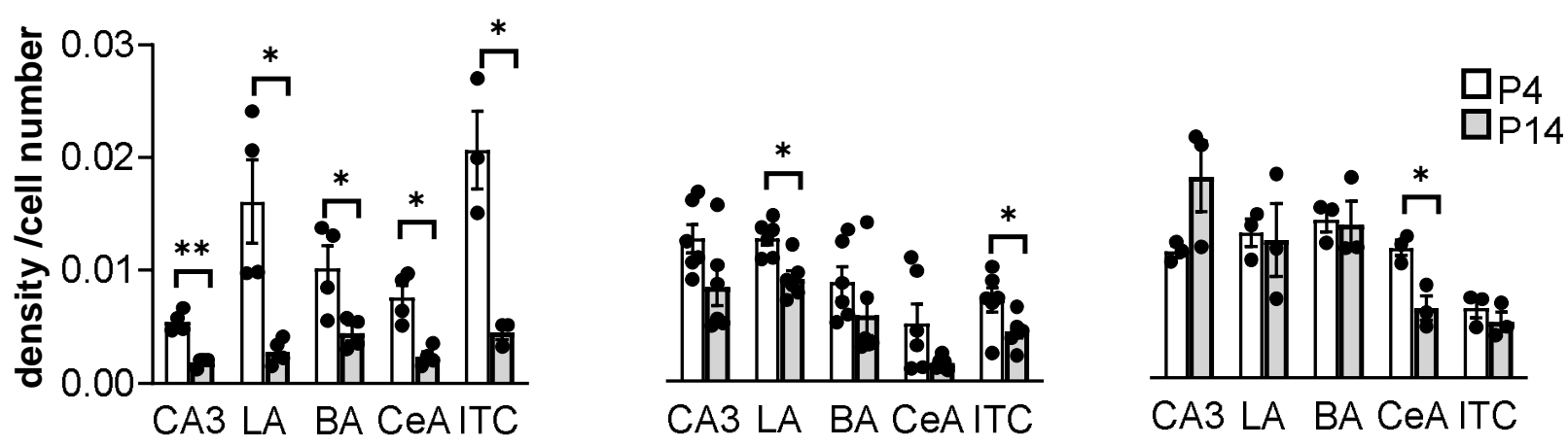
A

P4-7

P9-11

P14-16

P20-21

LA
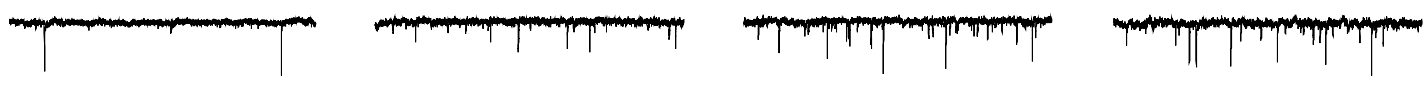

BA

CeA

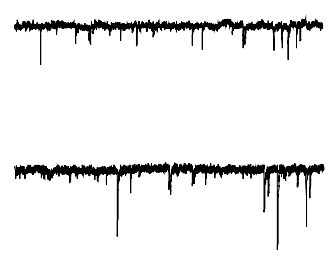

B

LA

BA

CeA
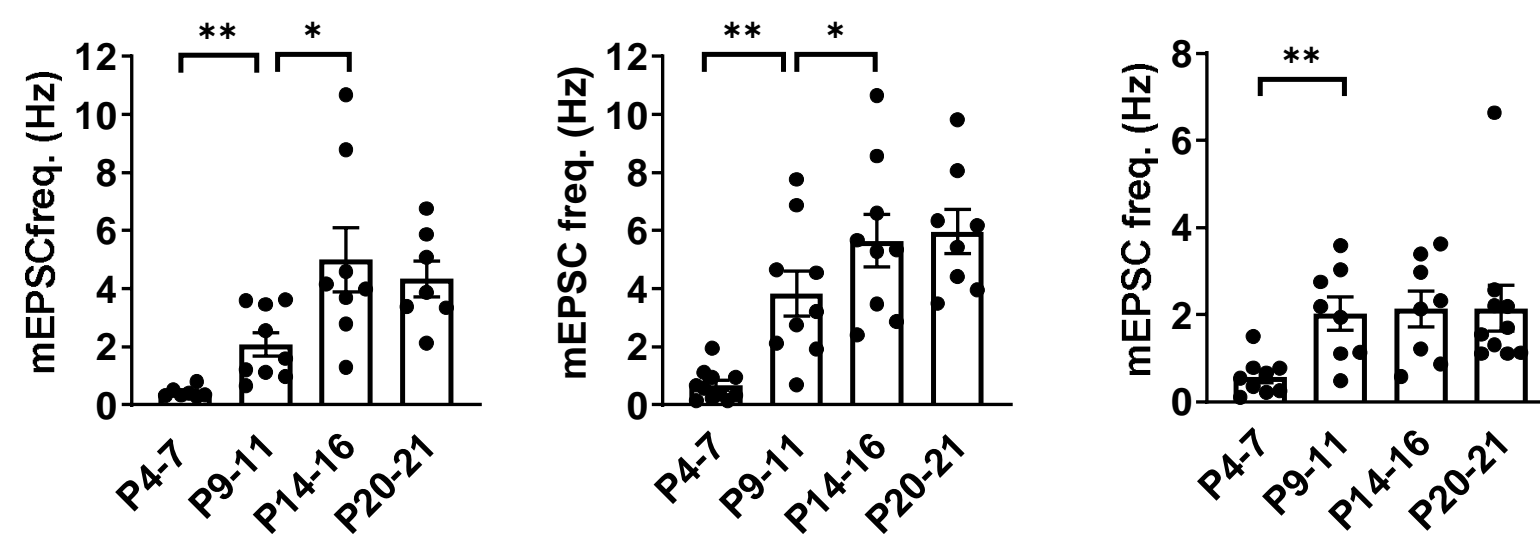

C

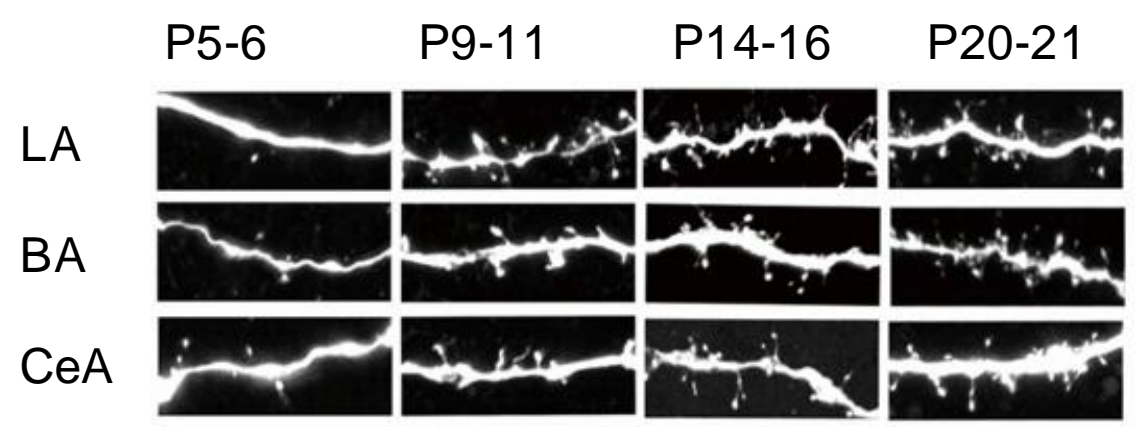

D

LA

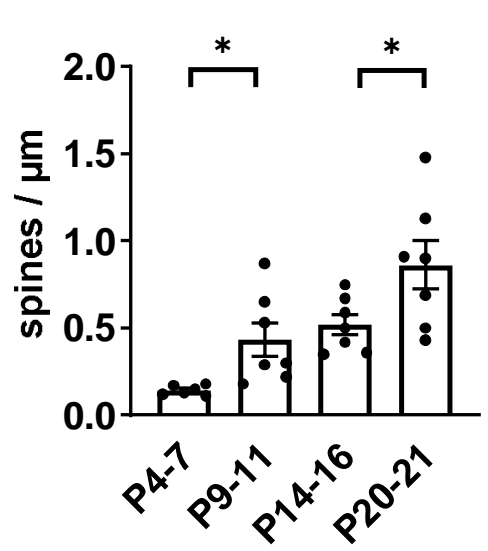

BA

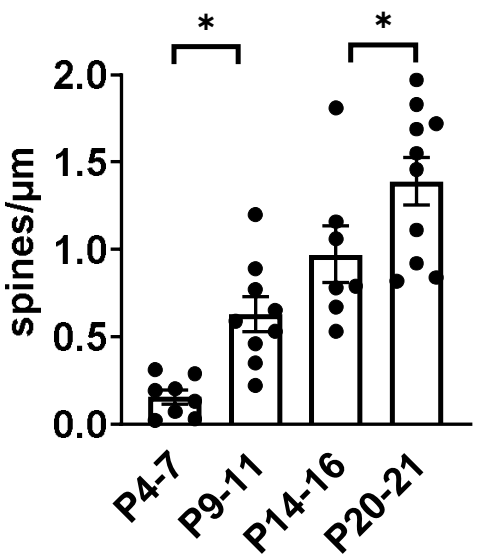

CeA

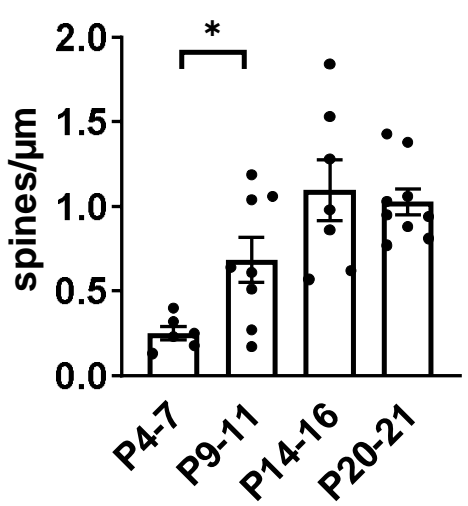


bioRxiv preprint doi: https://doi.org/10.1101/753103; this version posted August 30, 2019. The copyright holder for this preprint (which was

A LA P4-6 not certified by peer

BA P4-6

C LA P4-6
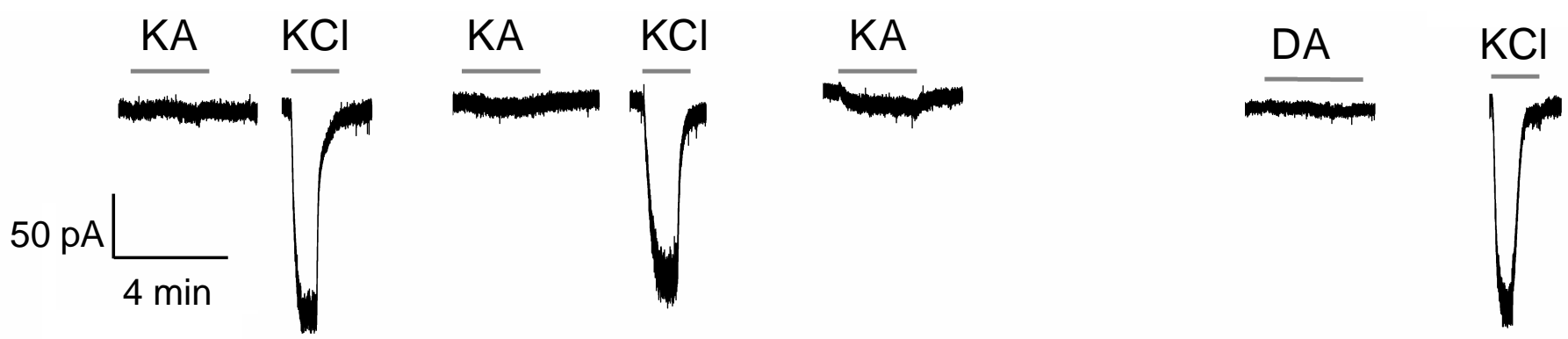

LA P 14-16

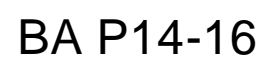

CeA P14-16

BA P4-6
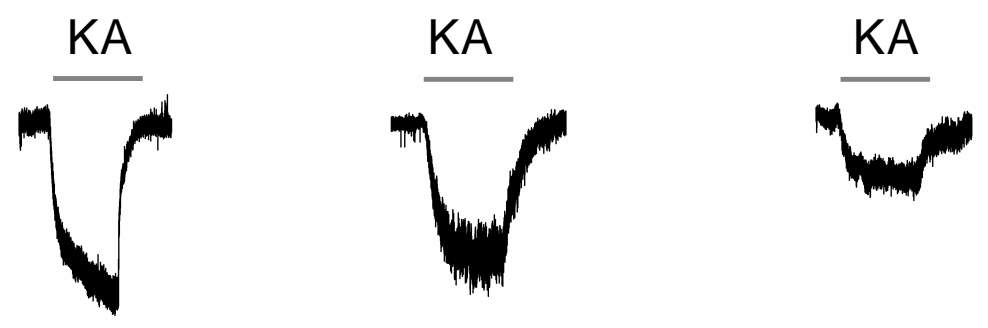

DA

$\mathrm{KCl}$

$50 \mathrm{pA} \frac{}{4 \mathrm{~min}}$

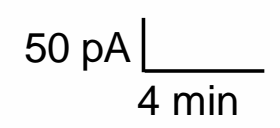

B
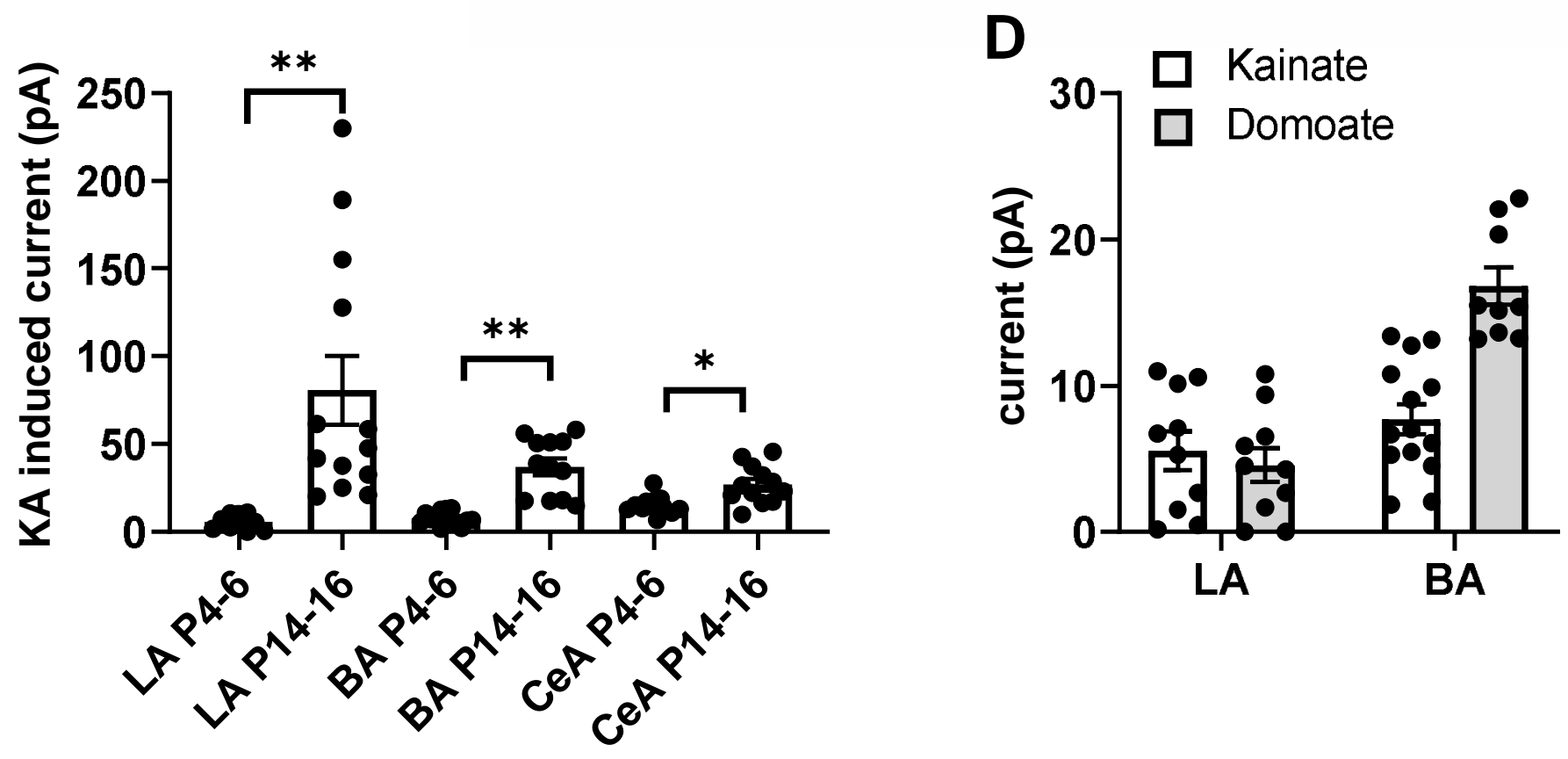
A LA

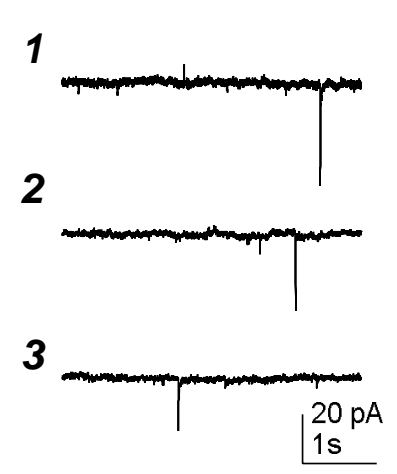

B BA
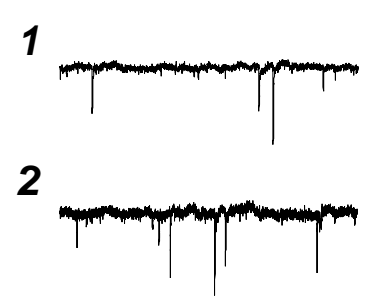

3

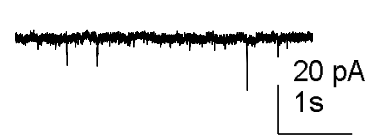

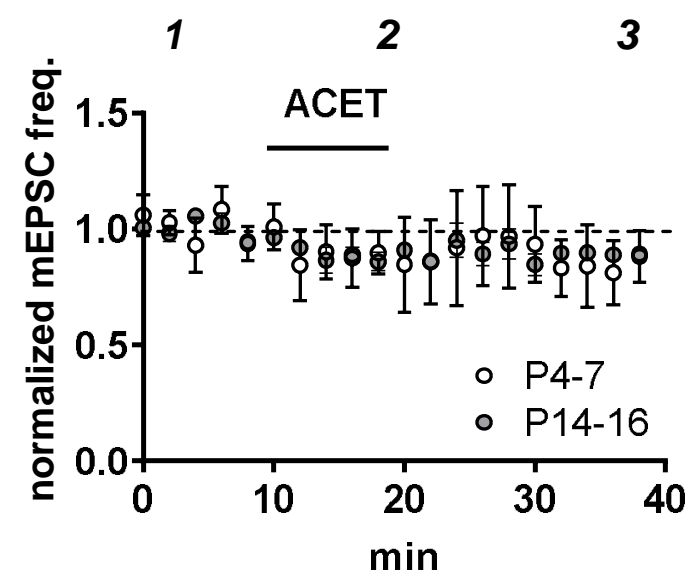

3

P4-7

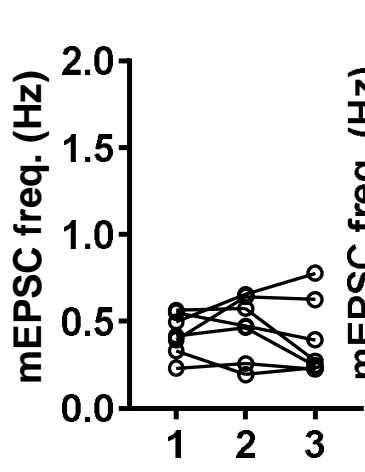

P14-16

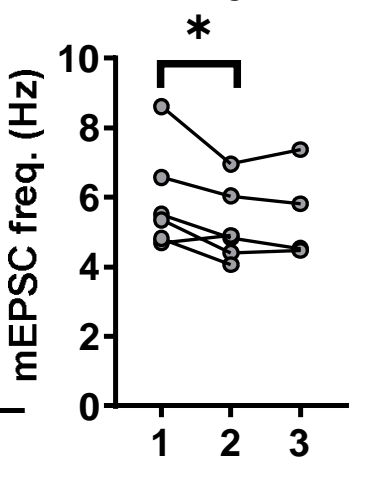

3

P4-7

$\mathrm{P} 14-16$
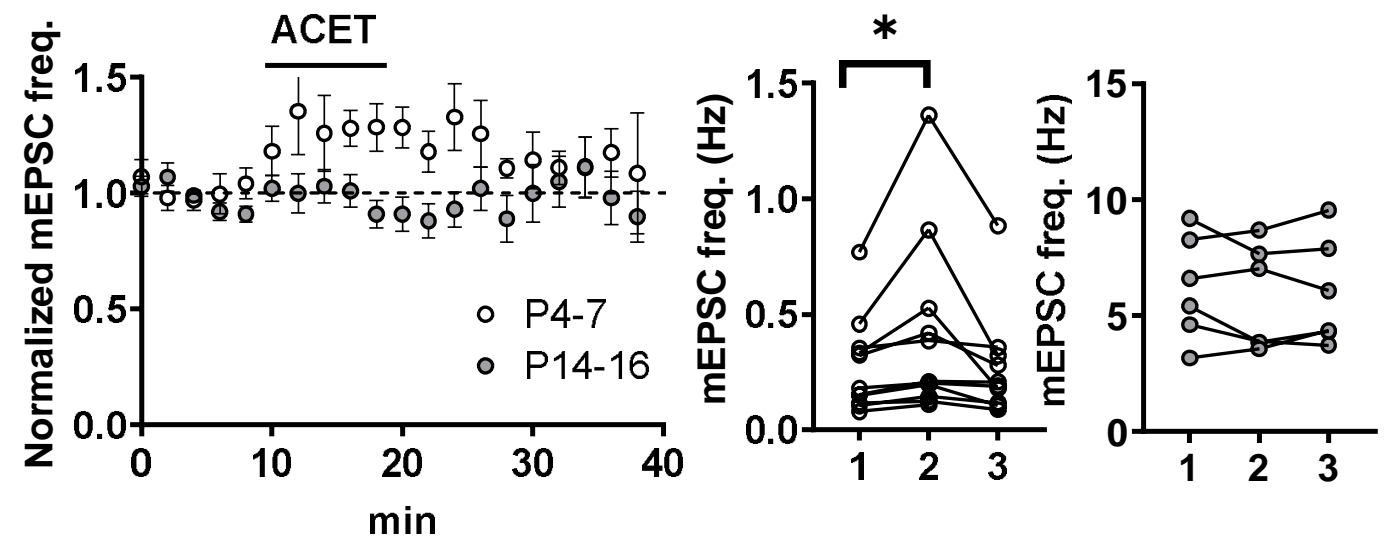

C $\mathrm{CeA}$
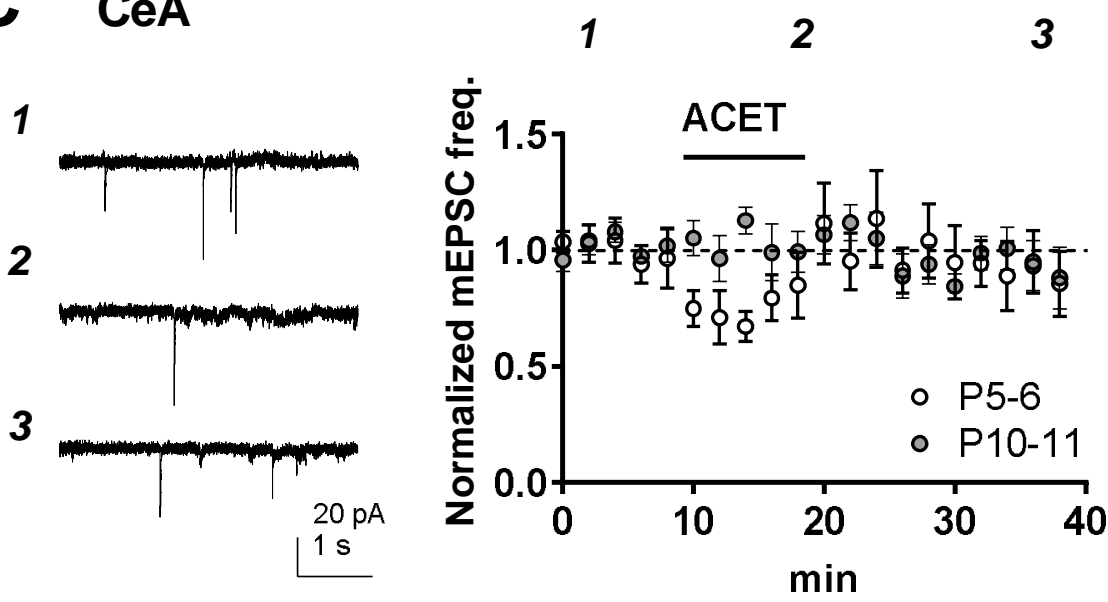

P5-6

P10-11
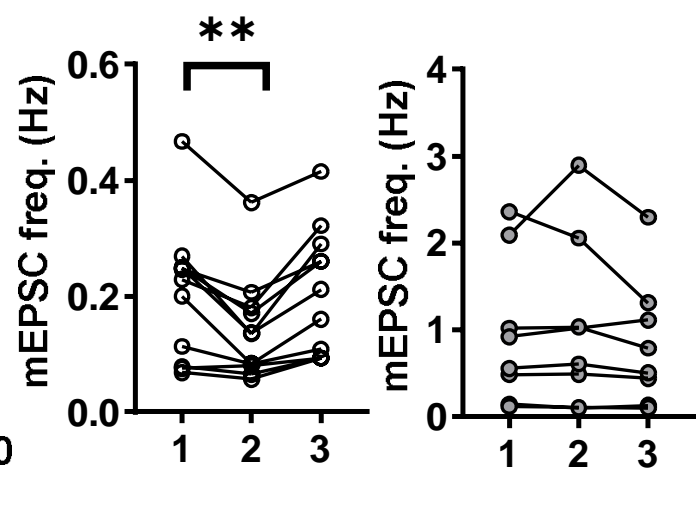
bioRxiv preprint doi: https://doi.org/10.1101/753103; this version posted August 30, 2019 . The copyright holder for this preprint (which was 1 not certified by geer review) is the anthor/funder. All rights reuse allowed without permissign.
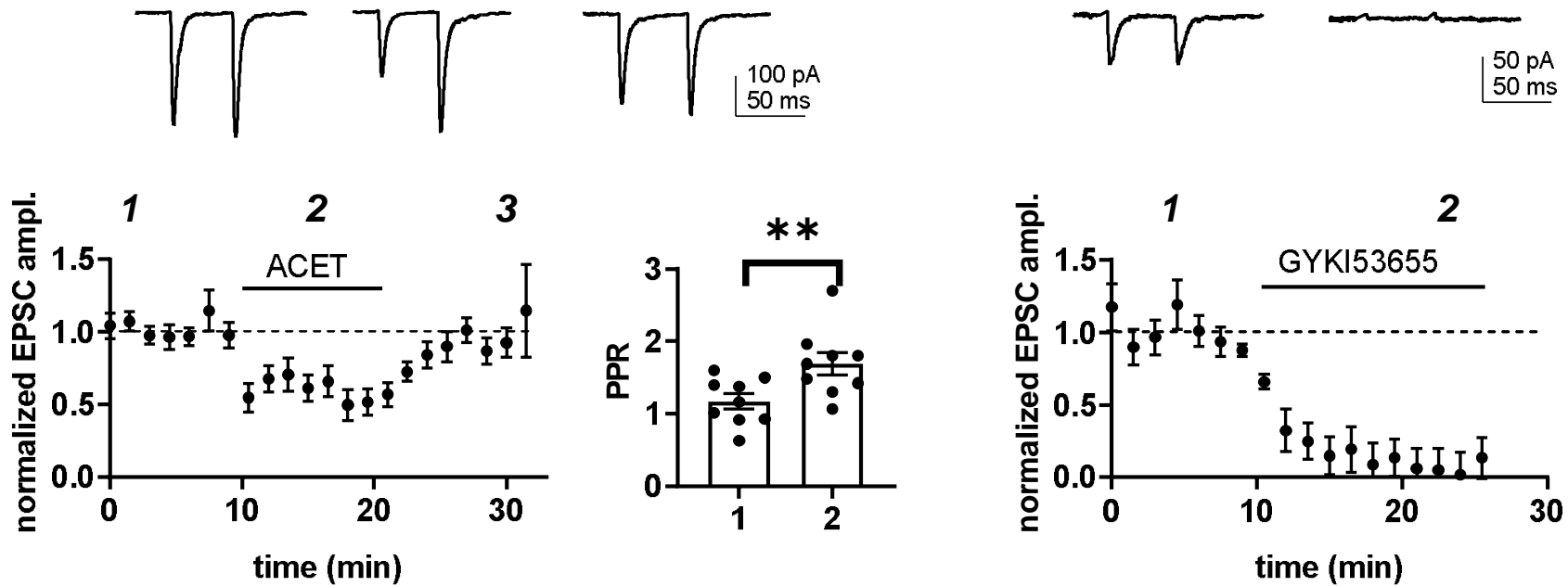

C

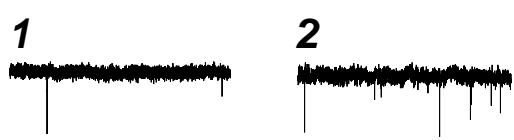

3
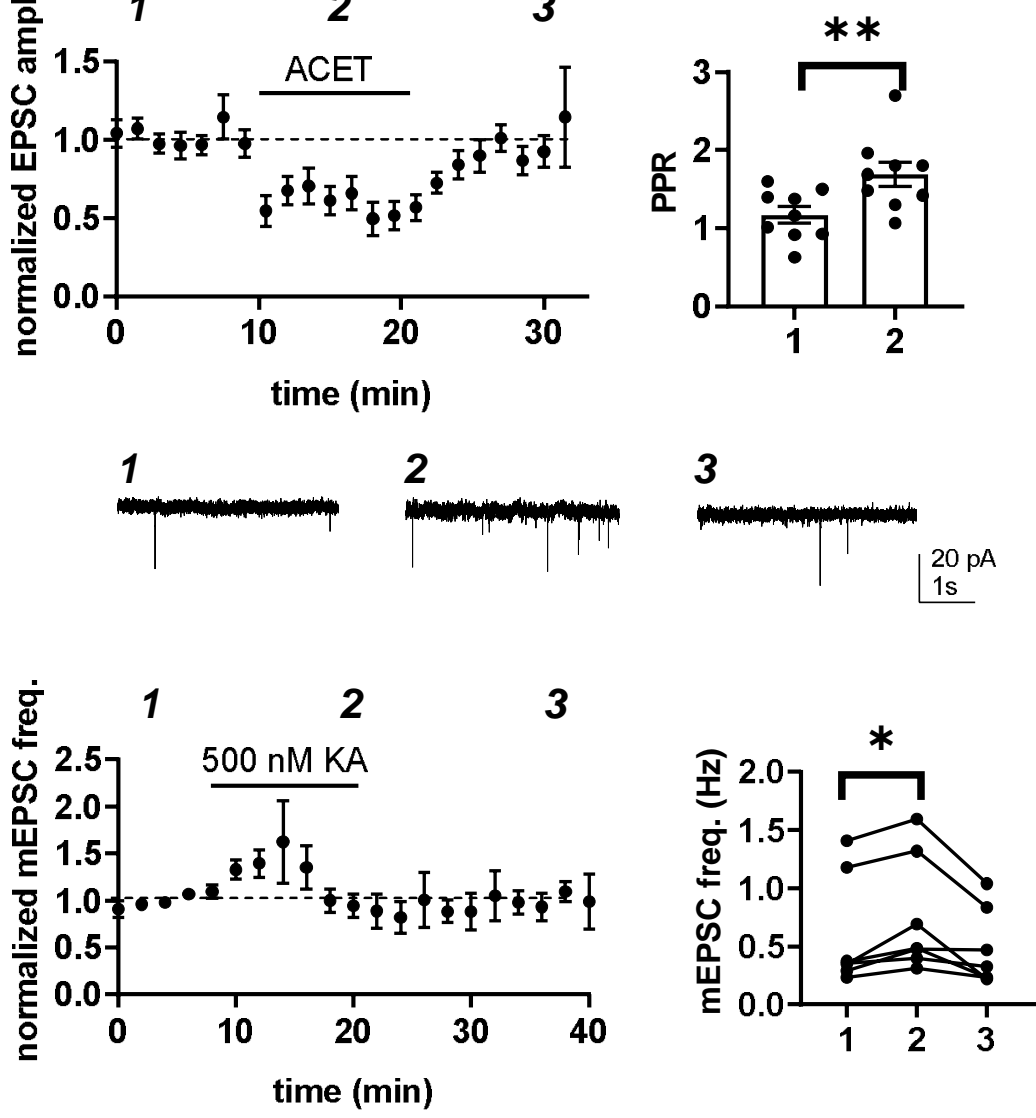

D
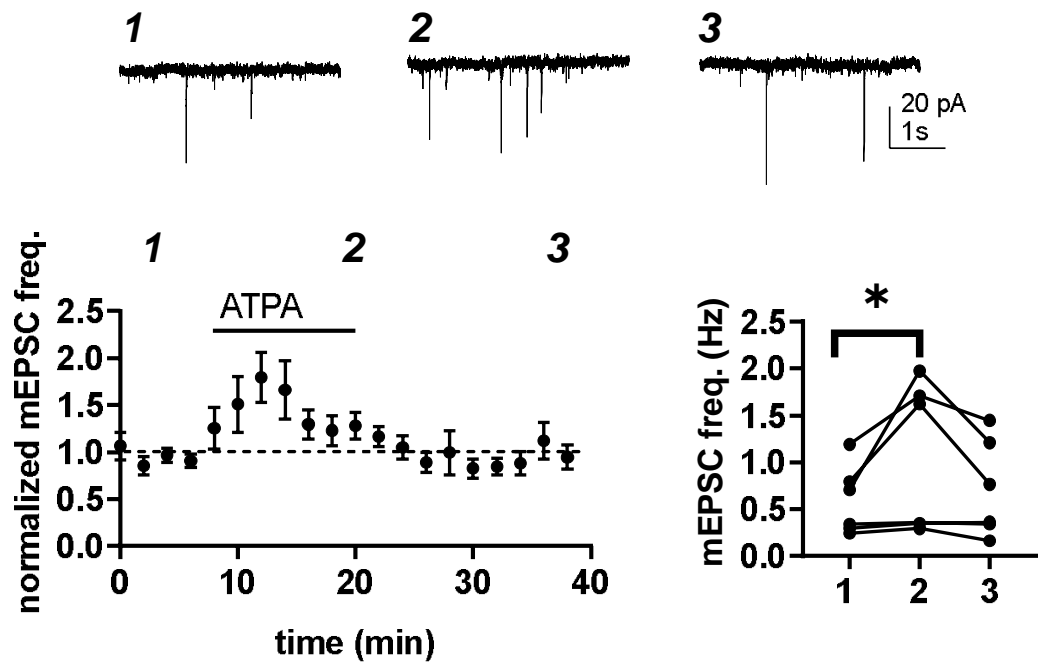

E

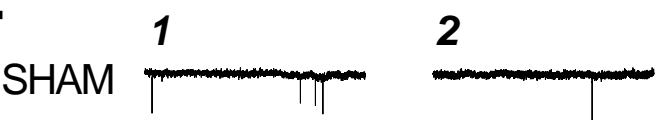

3

PTX
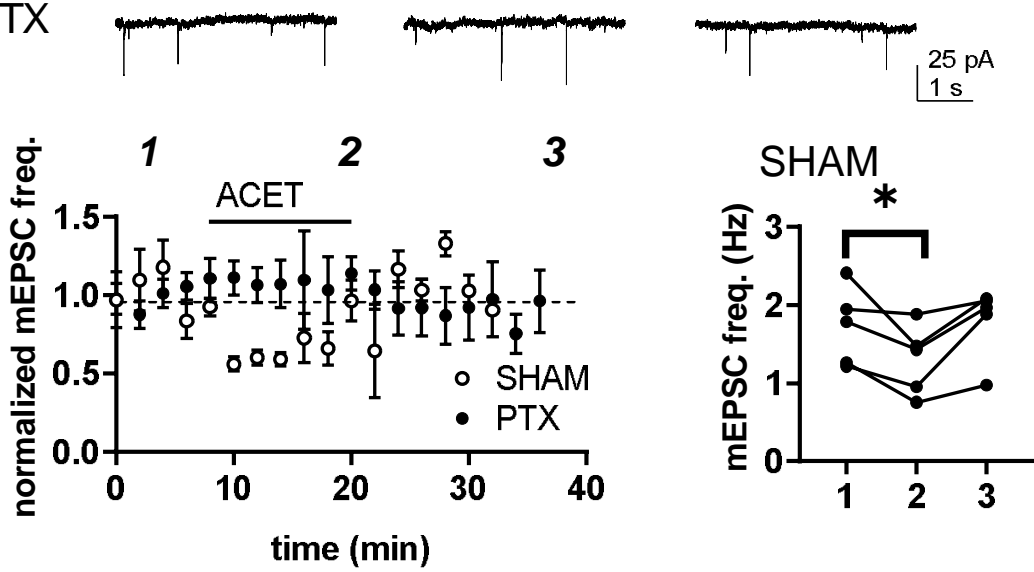

PTX

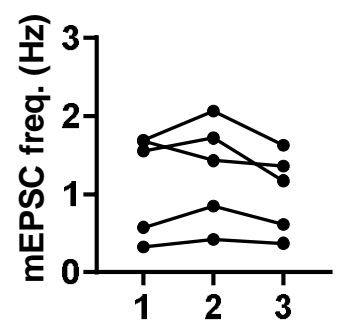


A

bioRxiv preprint doi: https://doi.org/10.1101/753103; this version posted August 30, 2019. The copyright holder for this preprint (which was not certified by peer review) is the author/fundar. All rights reserved. No reuse allowed without permission.
AAV8-CRE GFP
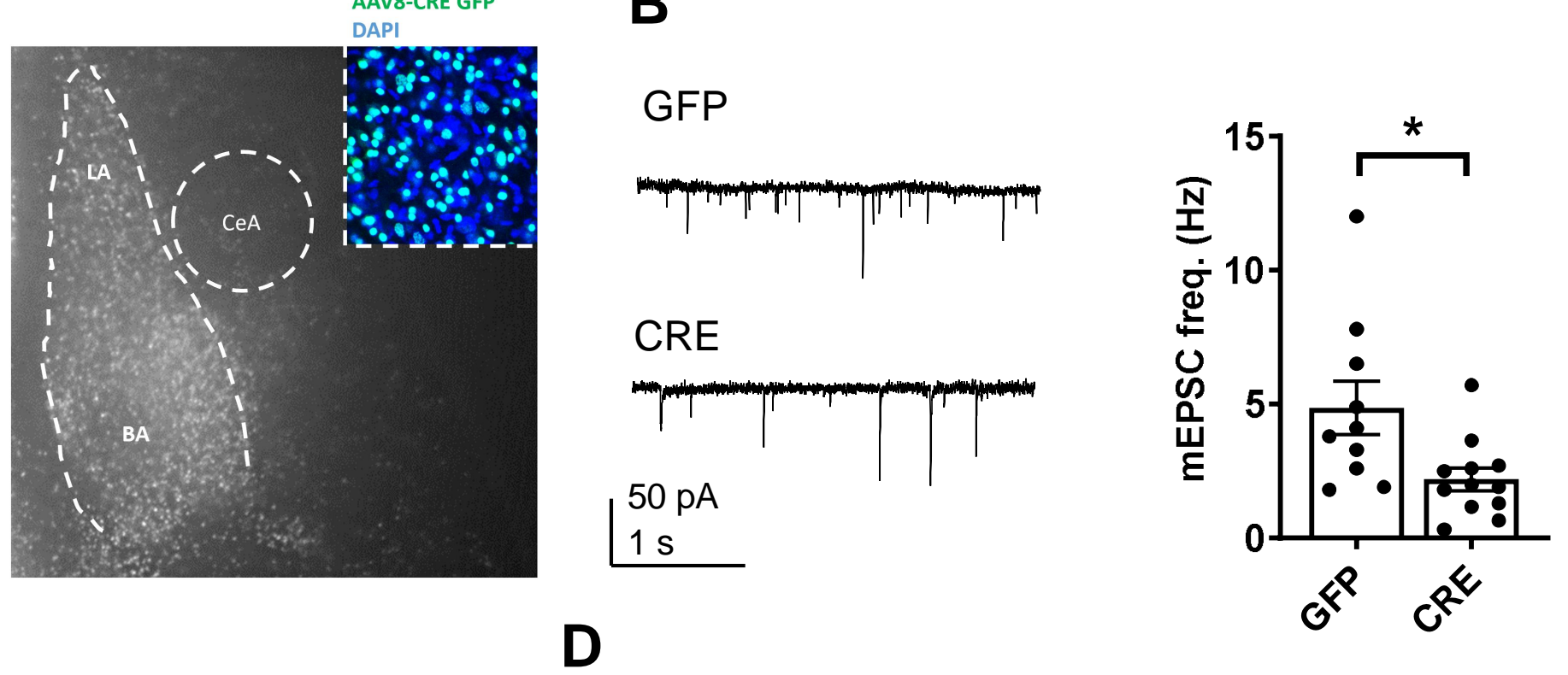

C
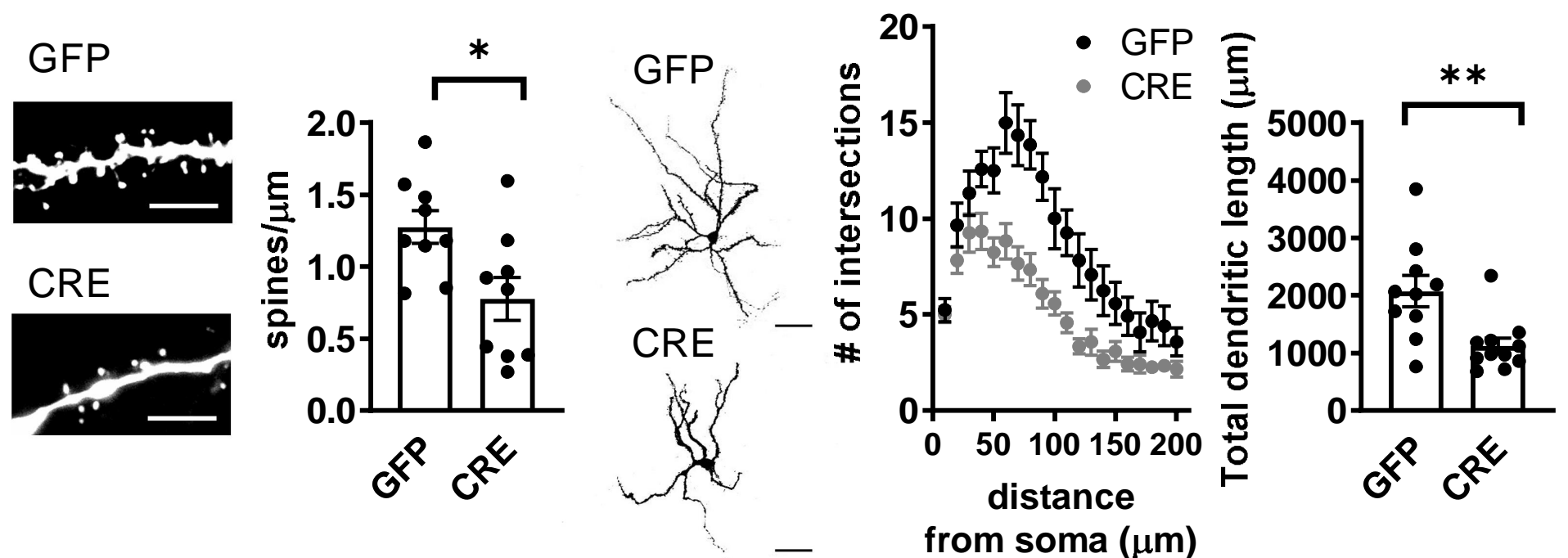

$\mathbf{E}$

LF

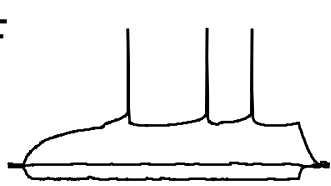

$\mathrm{RF}$
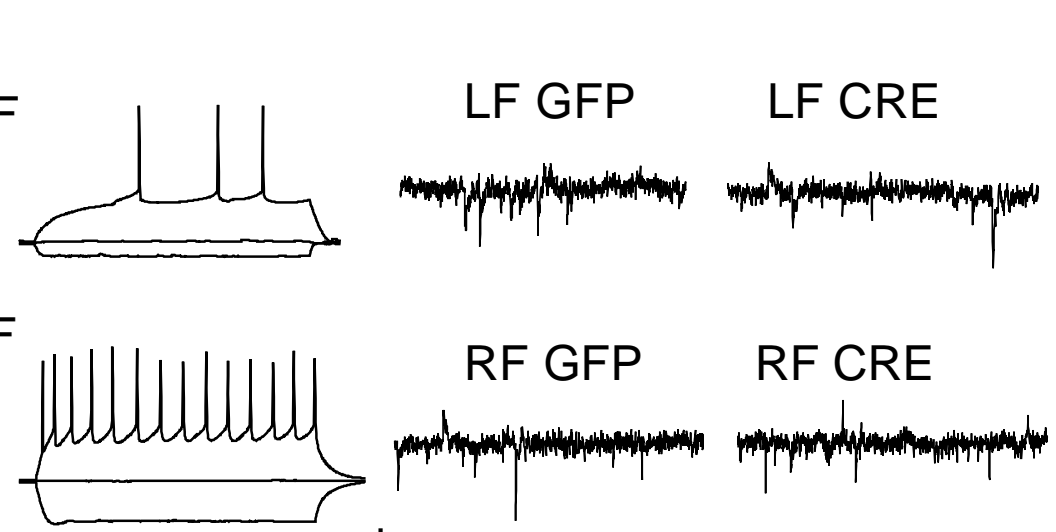

$50 \mathrm{mV}$
$100 \mathrm{~ms}$

\section{RF GFP RF CRE}

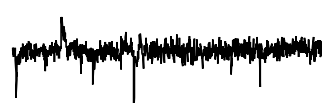

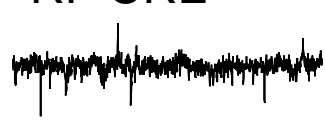
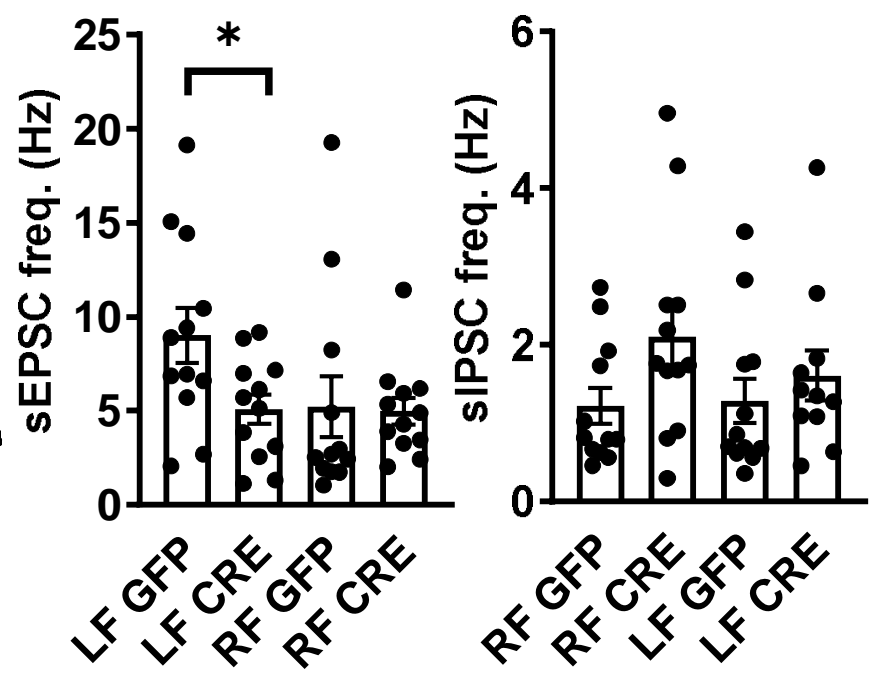
bioRxiv preprint doi: https://doi.org/10.1101/753103; this version posted August 30, 2019. The copyright holder for this preprint (which was not certified by peer review) is the author/funder. All rights reserved. No reuse allowed without permission.

A

Lenti - shRNA GFP

DAPI

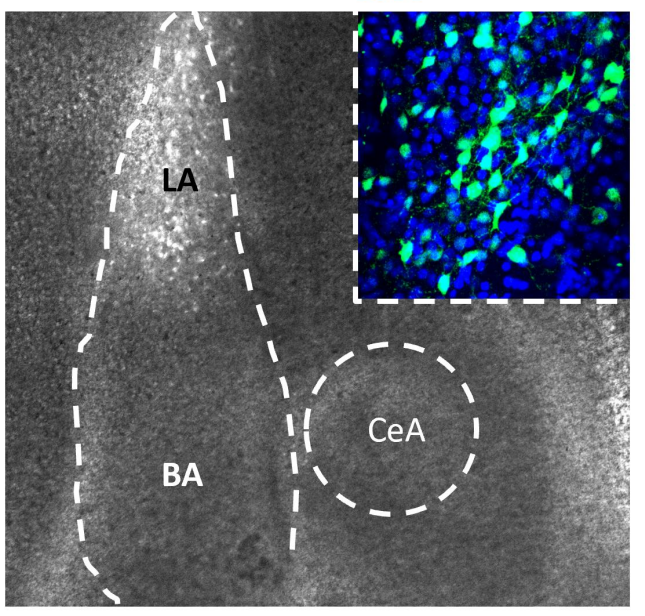

D

GFP

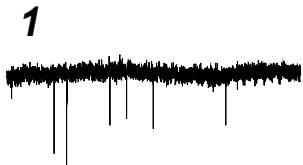

GluK1 oe

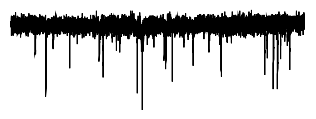

GluK1

shRNA

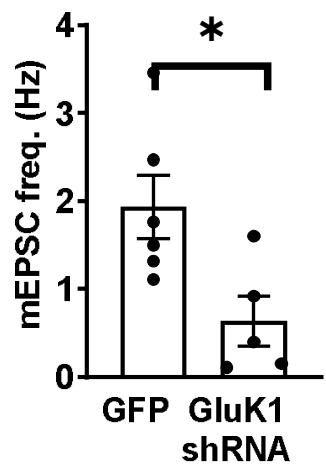

\section{$2 \quad 3$}

(1)
C

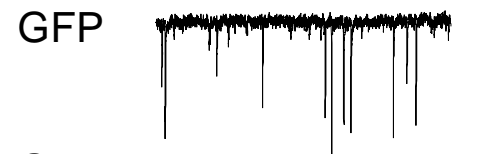

GluK1

oe

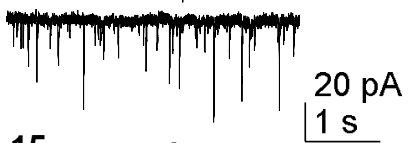

$20 \mathrm{pA}$
$1 \mathrm{~s}$
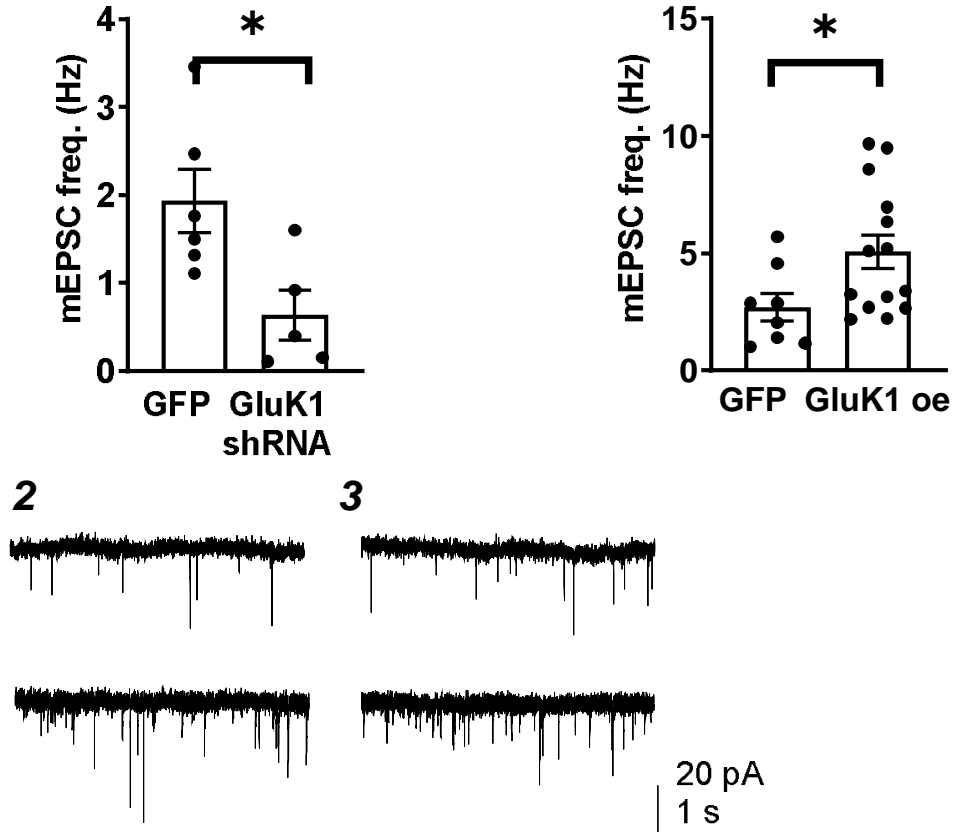

GluK1 oe
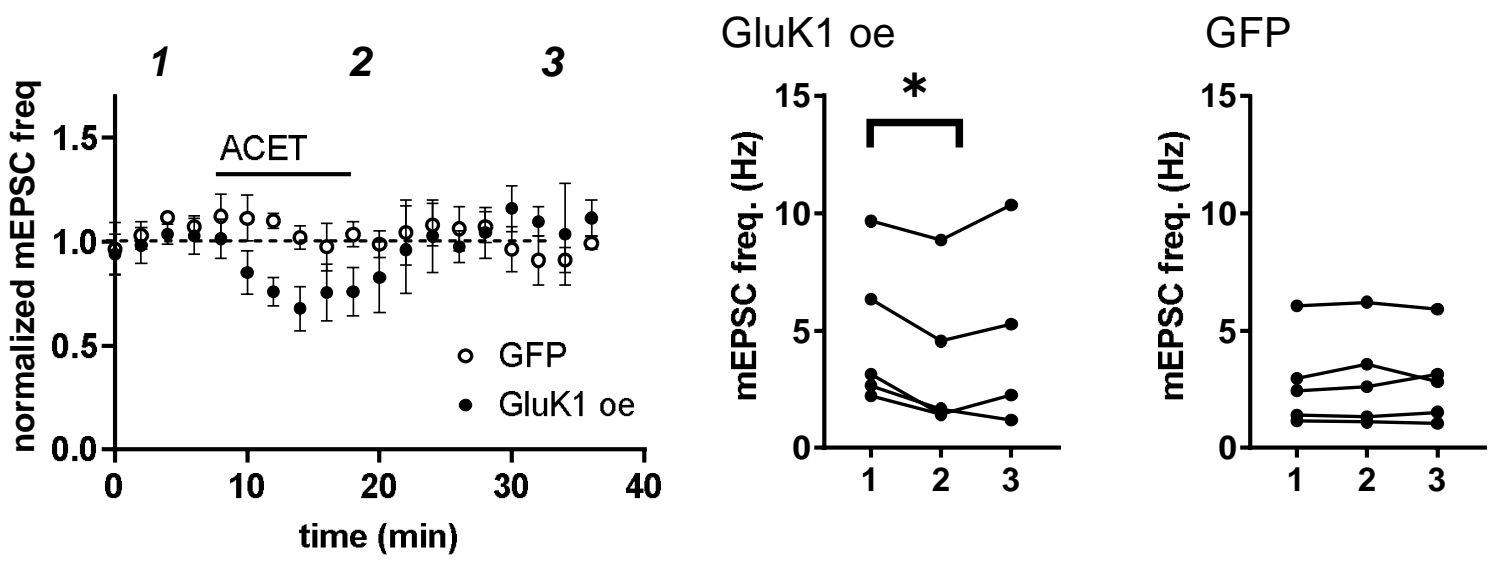

E
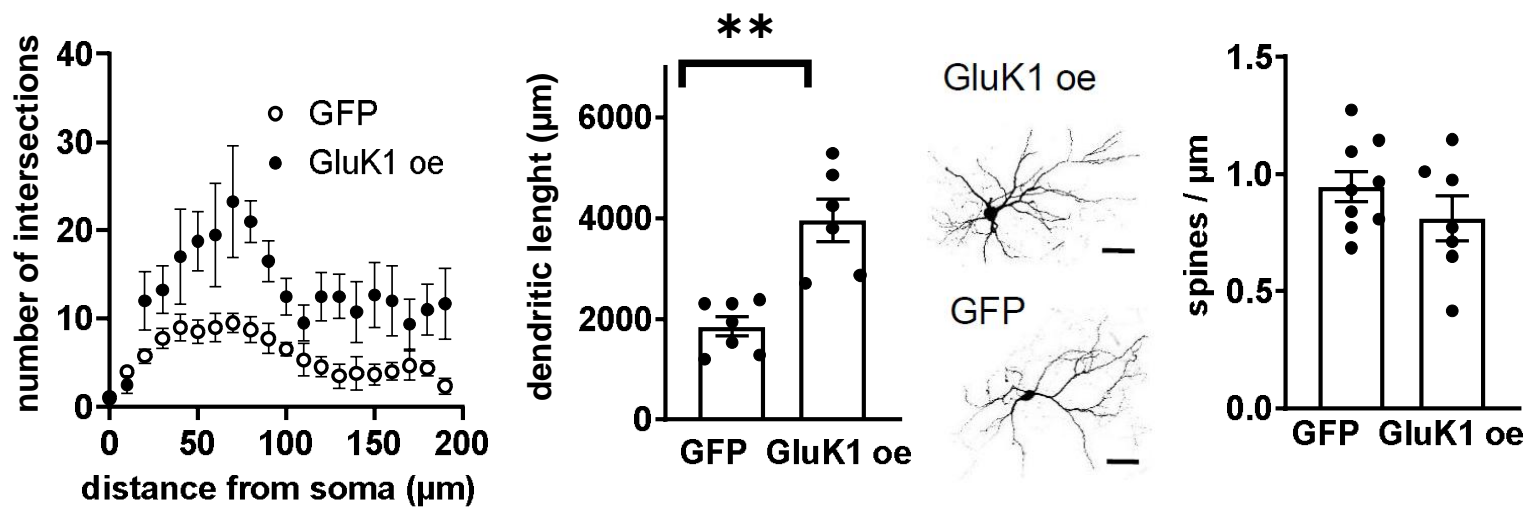

GluK1 oe

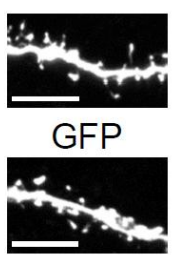




\section{Supplementary Figure $\mathbf{S 1}$}

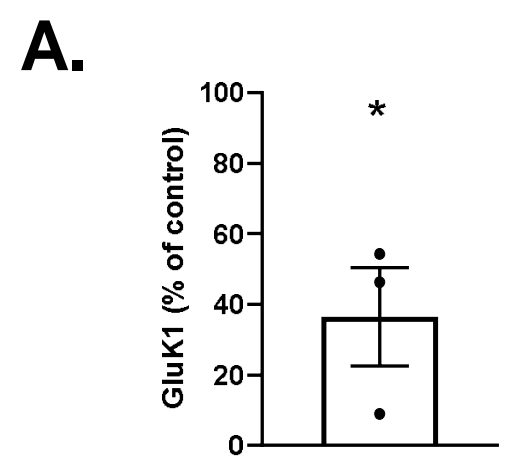

B.
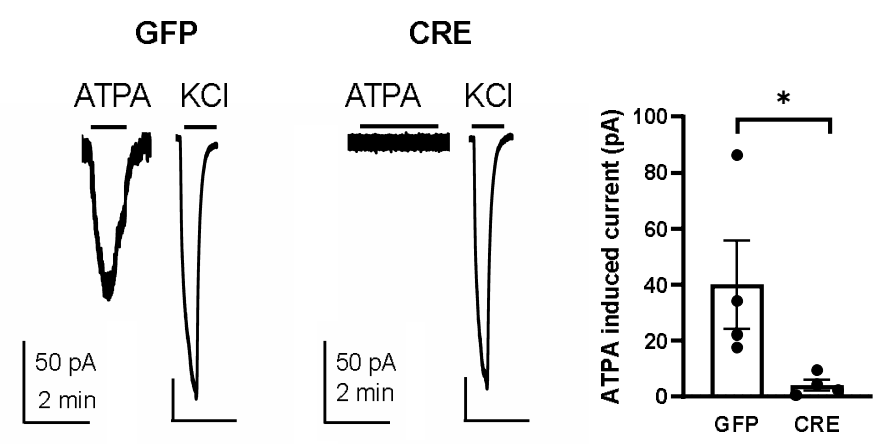

\section{Validation of the GluK1 cKO mouse model}

A. RT-qPCR results showing loss of GluK1 mRNA expression in the hippocampus (HC) of GluK ${ }^{\text {tmlc/tmlc }}$ mice 23 days after injection of AAV virus encoding for eGFP-Cre. Injection was done in 9 week old mice. The data represents the level of GluK1 mRNA expression in eGFPCre - injected $\mathrm{HC}$ as a percentage of the control (eGFP injected $\mathrm{HC}, \mathrm{n}=3$ for both groups) . * $p<0.05$, unpaired t-test.

B. Loss of GluK1 function in the LA neurons following eGFP-Cre injection in the GluK1 ${ }^{\text {tmlc/tmlc }}$ mice. Example traces and pooled data illustrating ATPA $(1 \mu \mathrm{M})$ induced currents in LA neurons in slices obtained from control (eGFP injected) but not in eGFP-Cre injected GluK1 ${ }^{\text {tm1c/tm1c }}$ mice (eGFP-Cre: $n=4$, eGFP: $n=4$; ANOVA; $p<0.05$ ). eGFP or eGFP-Cre encoding AAV viruses were injected to the BLA of adult GriK1 ${ }^{\text {tm1c/mm1c }}$ mice, acute slices were cut for electrophysiological analysis 21 days after injection. Agonist induced currents were recorded as described in the main article.

Methods for the RTqPCR. The whole hippocampi were dissected form the GriK1 tm1c mice, and stored in RNALater stabilization solution. RNA extraction and purification was done using the RNeasy M ini Kit (Qiagen), any remaining DNA was removed using DNA-free DNA Removal Kit (Thermo Fisher Scientific), and CDNA synthesis was carried out using RevertAid First Strand CDNA Synthesis Kit (Thermo Fisher Scientific) with oligo(dT)18 primers. Real-time quantitative PCR was done using forward primer AAACTGGTTCCTGACGGCAA and reverse primer CTGCTAGGTCAGCTCTGTGG. All samples were analysed in triplicate, and relative quantification of gene expression was analysed using the 2-ddCt method. 


\section{Supplementary Figure S2}
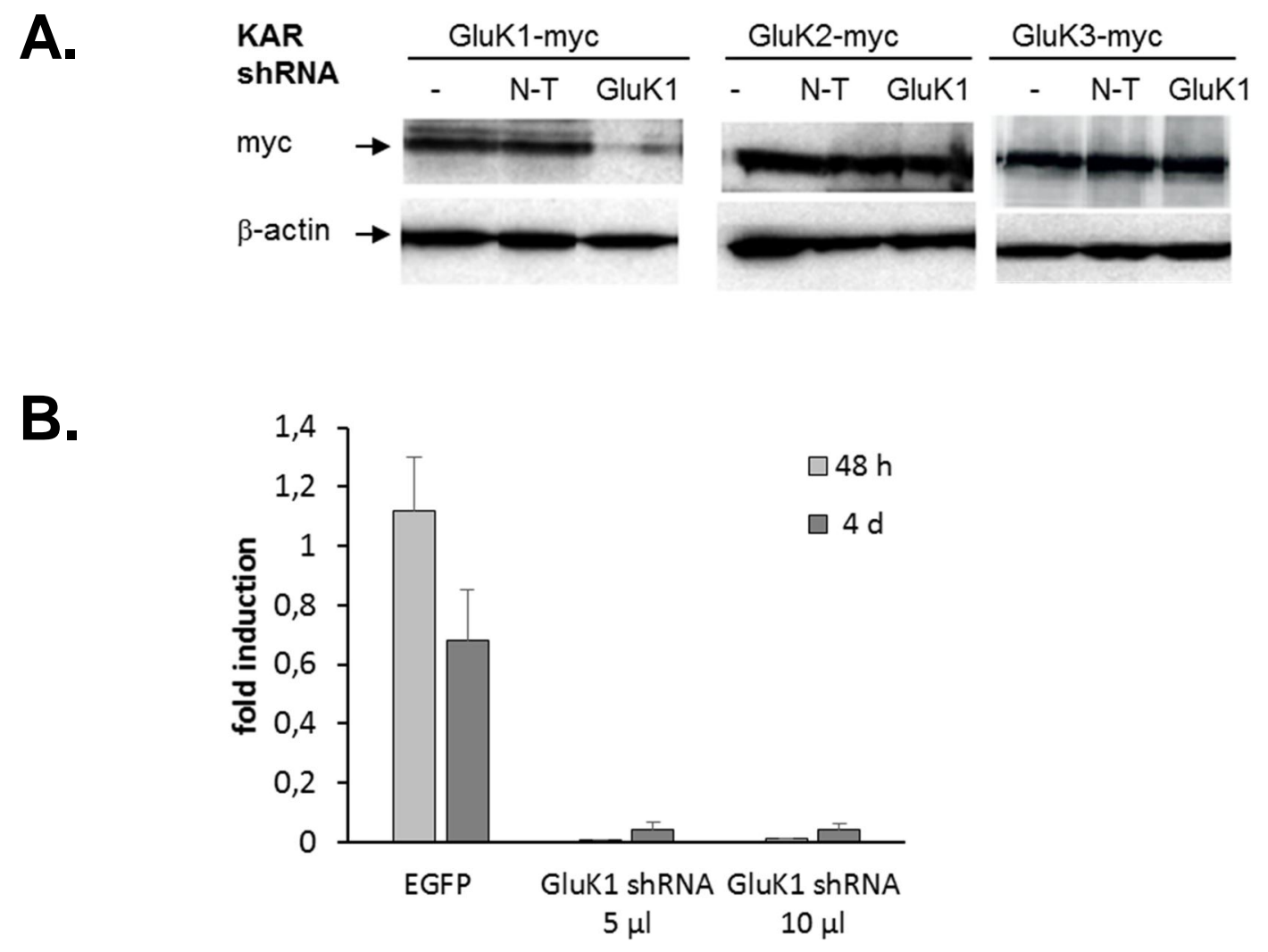

\section{Validation of the GluK1 shRNA}

A. A western blot illustrating that the GluK1 shRNA strongly inhibited expression of GluK1myc but not GluK2-myc or GluK3-myc in HEK293T cells.

B. RT-qPCR results showing that the lentiviral GluK1 shRNA construct strongly inhibited expression of endogenous GluK1 in dorsal root gangion (DRG) neurons within $48 \mathrm{~h}$ from infection.

\section{Methods:}

Seven different shRNA sequences against rat GluK1 in pLKO.1 vector (five obtained from Sigma Aldrich and two from TRC shRNA library, Biomedicum Helsinki Functional Genomics Unit) were tested for their efficiency to suppress expression of GluK1-myc and GluK2-myc and GluK3 -myc in HEK293T cells as described (Sakha et al., 2016). The TRC Clone ID: TRCN0000100308 was selected based on its efficiency and specificity to knock down expression of the target protein in the heterologous system. The shRNA target sequence (CCTGGACATTATCAGTCTCAA) was subcloned into a modified pLKO.1 vector where the puromycin resistance cassette was replaced with GFP under the synapsin -1 promoter (pLKO.1-syn1-EGFP). Lentiviral particles were produced in HEK293T cells as described (Vesikansa et al., 2012). The lentiviral GluK1 shRNA was then further tested in primary dorsal root ganglion neurons (DRG) where GluK1 KAR subunits are endogenously expressed. The 
neurons were prepared and cultured as described (Kysenius et al. 2012) and infected with the shRNA encoding lentiviral vectors at 4 and 7 DIV. For quantification of the GluK1 mRNA levels, total RNA was isolated from two independent cultures at 9 DIV and 12 DIV and RT-qPCR with GluK1 selective primers was carried out essentially as described (Sakha et al., 2016).

\section{References:}

Kysenius K, Muggalla P, Mätlik K, Arumäe U, Huttunen HJ. (2012) PCSK9 regulates neuronal apoptosis by adjusting ApoER2 levels and signaling. Cell M ol Life Sci. 69(11):1903-16.

Sakha P, Vesikansa A, Orav E, Heikkinen J, Kukko-Lukjanov TK, Shintyapina A, Franssila S, Jokinen V, Huttunen HJ, Lauri SE. (2016) Axonal Kainate Receptors Modulate the Strength of Efferent Connectivity by Regulating Presynaptic Differentiation. Front Cell Neurosci. 10:3.

Vesikansa A, Sakha P, Kuja-Panula J, M olchanova S, Rivera C, Huttunen HJ, Rauvala H, Taira T, Lauri SE. (2012) Expression of GluK1c underlies the developmental switch in presynaptic kainate receptor function. Sci Rep.2:310.

\section{Contributions:}

Tiina-Kaisa Kukko-Lukjanov, Western blots in HEK cells, lentiviral vectors Ester Orav, RT-qPCR

Kärt Mätlik , DRG cultures 